\title{
Transcriptional response of rat frontal cortex following acute In Vivo exposure to the pyrethroid insecticides permethrin and deltamethrin
}

\author{
Joshua A Harrill1 ${ }^{1}$ Zhen $\mathrm{Li}^{2}$, Fred A Wright ${ }^{2}$, Nicholas M Radio ${ }^{3}$, \\ William R Mundy ${ }^{3}$, Rogelio Tornero-Velez ${ }^{4}$ and Kevin M Crofton*3
}

\begin{abstract}
Address: ${ }^{1}$ Curriculum in Toxicology, University of North Carolina at Chapel Hill, Chapel Hill, North Carolina, USA, ${ }^{2}$ Department of Biostatistics and the Carolina Environmental Bioinformatics Research Center, University of North Carolina at Chapel Hill, Chapel Hill, North Carolina, USA, ${ }^{3}$ Neurotoxicology Division, National Health and Environmental Effects Research Laboratory, Office of Research and Development, United State Environmental Protection Agency, Research Triangle Park, North Carolina, USA and ${ }^{4}$ Human Exposure and Atmospheric Sciences Division, National Exposure Research Laboratory, Office of Research and Development, United States Environmental Protection Agency, Research Triangle Park, North Carolina, USA
\end{abstract}

Email: Joshua A Harrill - harrill.josh@epa.gov; Zhen Li - li.zhen@epa.gov; Fred A Wright - fwright@bios.unc.edu; Nicholas M Radio - radio.nick@epa.gov; William R Mundy - mundy.william@epa.gov; Rogelio Tornero-Velez - tornero-velez.rogelio@epa.gov; Kevin M Crofton* - crofton.kevin@epa.gov

* Corresponding author

Published: 18 November 2008

BMC Genomics 2008, 9:546 doi:10.1 |86/|47|-2164-9-546
Received: 7 May 2008

Accepted: 18 November 2008

This article is available from: http://www.biomedcentral.com//47I-2/64/9/546

(c) 2008 Harrill et al; licensee BioMed Central Ltd.

This is an Open Access article distributed under the terms of the Creative Commons Attribution License (http://creativecommons.org/licenses/by/2.0), which permits unrestricted use, distribution, and reproduction in any medium, provided the original work is properly cited.

\begin{abstract}
Background: Pyrethroids are neurotoxic pesticides that interact with membrane bound ion channels in neurons and disrupt nerve function. The purpose of this study was to characterize and explore changes in gene expression that occur in the rat frontal cortex, an area of CNS affected by pyrethroids, following an acute low-dose exposure.
\end{abstract}

Results: Rats were acutely exposed to either deltamethrin $(0.3-3 \mathrm{mg} / \mathrm{kg})$ or permethrin $(\mathrm{I}-\mathrm{I} 00 \mathrm{mg} / \mathrm{kg}) \mathrm{followed} \mathrm{by}$ collection of cortical tissue at 6 hours. The doses used range from those that cause minimal signs of intoxication at the behavioral level to doses well below apparent no effect levels in the whole animal. A statistical framework based on parallel linear (SAM) and isotonic regression (PIR) methods identified 95 and 53 probe sets as dose-responsive. The PIR analysis was most sensitive for detecting transcripts with changes in expression at the NOAEL dose. A sub-set of genes (Camklg, Ddc, Gpd3, c-fos and Egrl) was then confirmed by qRT-PCR and examined in a time course study. Changes in mRNA levels were typically less than 3-fold in magnitude across all components of the study. The responses observed are consistent with pyrethroids producing increased neuronal excitation in the cortex following a low-dose in vivo exposure. In addition, Significance Analysis of Function and Expression (SAFE) identified significantly enriched gene categories common for both pyrethroids, including some relating to branching morphogenesis. Exposure of primary cortical cell cultures to both compounds resulted in an increase $(25 \%)$ in the number of neurite branch points, supporting the results of the SAFE analysis.

Conclusion: In the present study, pyrethroids induced changes in gene expression in the frontal cortex near the threshold for decreases in ambulatory motor activity in vivo. The penalized regression methods performed similarly in detecting dose-dependent changes in gene transcription. Finally, SAFE analysis of gene expression data identified branching morphogenesis as a biological process sensitive to pyrethroids and subsequent in vitro experiments confirmed this predicted effect. The novel findings regarding pyrethroid effects on branching morphogenesis indicate these compounds may act as developmental neurotoxicants that affect normal neuronal morphology. 


\section{Background}

Pyrethroid insecticides represent a significant percentage of the world insecticide market [1]. This usage results in an increased potential for human exposure. Pyrethroid residues have been detected in sediments from agricultural run-off [2], residential dust samples [3] and childcare centers [4]. Pyrethroid metabolites have also been detected in human urine [5]. A major research focus for pyrethroids is determining if compounds belonging to this chemical class act through the same or similar mechanisms-of-action to produce similar adverse health outcomes [6].

Pyrethroids disrupt nervous system function by interacting with membrane bound ion channels and altering their normal gating kinetics [7]. The primary molecular targets of pyrethroids are neuronal voltage-sensitive sodium channels (VSSCs) [6]. Prolongation of whole-cell $\mathrm{Na}^{+}$currents has been observed in a variety of cultured nervous system tissues exposed to pyrethroids [8-10]. Furthermore, in vitro studies utilizing heterologous expression systems have demonstrated that pyrethroids increase sodium current through VSSC isoforms $\left(\mathrm{Na}_{\mathrm{v}} 1.2, \mathrm{Na}_{\mathrm{v}} 1.4\right.$ \& $\mathrm{Na}_{\mathrm{v}} 1.8$ ), although the complete complement of mammalian VSSCs have not been examined for pyrethroid sensitivity [11-13]. Pyrethroids may also alter the gating kinetics of both neuronal voltage-sensitive $\mathrm{Ca}^{+2}$ (VGCCs) and voltage-sensitive $\mathrm{Cl}^{-}$channels [14-17]. Isoforms of all of the aforementioned molecular targets are expressed in the plasma membrane of mammalian neuronal cells.

Pyrethroids affect nervous system function by producing hyperexcitability in neurons and changing neuronal firing rates [18-21]. Acute manifestations of neurotoxicity on mammalian and insect species result from increased neuronal hyperexcitability driven by the actions of pyrethroids at their molecular target sites, primarily VSSCs [21]. Under normal conditions, neuronal excitation at the membrane results in the activation of intracellular signaling pathways that control the induction of gene expression [22]. In some cases, these transcriptional responses led to persistent adaptive changes in cellular functions (i.e. neuronal plasticity) $[23,24]$. Neuroactive chemicals that alter firing patterns or disrupt neurotransmission trigger the induction of unique groups of gene transcripts which may in turn impact neuronal function [25-27]. While alterations in neuronal excitability are critical events in the toxiciological mechanism-of-action for pyrethroids, the impact of pyrethroid-induced neuronal hyperexcitability on intracellular signaling pathways and inducible gene-regulatory networks is unknown.

The neuronal substrates that mediate acute pyrethroid neurotoxicity in vivo are unknown and it is likely that multiple brain regions are involved. However, previous stud- ies have demonstrated rapid accumulation of pyrethroids in the cortex following an acute oral dose, disruption of cortical neuronal firing patterns both in vivo and in vitro, and induction of gene products known to be upregulated following neuronal excitation [18,28-32]. Presently, the cortex is one of the few brain regions where pharmacokinetic, electrophysiological and biochemical data are available for pyrethroids. These data provide a significant weight of evidence that this brain region may be sensitive to acute pyrethroid exposures. The present study aims to characterize the effects of acute pyrethroid exposure on gene expression in the cortex.

In the present study Affymetrix GeneChip ${ }^{\circledR}$ microarrays were used to characterize the global transcriptional response of rat frontal cortex following an acute oral exposure to two model pyrethroids: permethrin and deltamethrin. The dose ranges used included doses that cause minimal neurotoxic signs, as well as doses below apparent 'no adverse effect levels' (NOAEL) in in vivo behavioral studies of motor function [33]. Differences in potency between the two compounds are due to differing pharmacokinetic profiles and likely varying pharmacodynamic activities $[12,28,30,32]$. In the present study, low doses were used to minimize any potential transcriptional changes which may be due solely to excessive systemic toxicity at high pyrethroid doses. Primary goals of this study were to: 1) to use a previously established linear regression (SAM) and a novel isotonic (PIR) regression method $[34,35]$ as discovery and prioritization tools for identification of dose-dependent changes in gene transcription, and 2) to compare the performance of these methods, 3) to confirm pyrethroid-sensitive transcriptional changes in a selected sub-set of genes using qRTPCR, 4) to examine the time course of these changes and 5) to utilize functional category level analysis (SAFE) [36] to identify pyrethroid sensitive cellular processes.

Dose-dependent changes in the transcription of several genes (Camk1g, Ddc, Gpd3, c-fos and Egr1) were discovered and successfully confirmed. Data from qRT-PCR experiments demonstrated clear qualitative similarities in the transcriptional response produced by both compounds. In addition, based on the SAFE analysis results, the hypothesis that pyrethroids can affect neuronal branching morphology was tested in an in vitro model of cortical neuron development. An increase ( $25 \%)$ in the number of neuronal branch points was observed. This may represent a novel aspect of pyrethroid neurotoxicity that to date has not been examined.

\section{Methods \\ Chemicals}

Permethrin (92.0\% purity, isomer composition: $40 \%$ cis, $60 \%$ trans, $1: 1$ ratio of $1 R \& 1 S)$ and deltamethrin $(98.9 \%$ 
purity, isomer composition: $100 \% 1 R, 3 R, \alpha S)$ were generously donated by FMC Corporation (Philadelphia, PA) and Bayer Cropscience (Research Triangle Park, NC), respectively. Pyrethroids were dissolved in corn oil (Sigma-Aldrich, St. Louis, MO) at 1, 10, $40 \& 100 \mathrm{mg} / \mathrm{mL}$ permethrin and $0.3,1 \& 3 \mathrm{mg} / \mathrm{mL}$ deltamethrin. Dosing volume was $1 \mathrm{~mL} / \mathrm{kg}$.

\section{Animal Care and Treatment}

Male Long-Evans rats (49-62 days of age) were obtained from Charles River Laboratories (Wilmington, MA) Housing conditions were identical to those used in Wolansky et al. (2006) [33]. The facility was approved by the American Association for Accreditation of Laboratory Animal Care (AAALAC) and all experimental procedures were approved in advance by the US EPA, NHEERL Animal Care and Use Committee.

Four cohorts of animals were used in this study (Table 1). Cohort 1 was used for preliminary data collection to demonstrate that the selected doses of the two compounds would alter gene transcription. Cohort 2 replicated these findings and expanded group sizes. Cohorts $1 \& 2$ were combined for microarray data analyses. Cohort 3 was examined exclusively by quantitative real-time RT-PCR (qRT-PCR). These dose-response cohorts $(\# 1,2,3)$ were exposed on separate days. All dosing occurred between 06:30 and 07:00 hours, counterbalanced across time of day, and the last test subject euthanized before 18:00 hours. Cohort 4 was used in qRT-PCR time course studies and dosed with $3 \mathrm{mg} / \mathrm{kg}$ deltamethrin, $100 \mathrm{mg} / \mathrm{kg}$ permethrin or vehicle. Each time point contained pyrethroidtreated and time-matched vehicle controls and all test subjects were dosed and euthanized between 07:30 \& 17:30 hours. In all cohorts, test subjects were removed from the colony suite $1 \mathrm{~h}$ prior to dosing and allowed to acclimate in a quiet holding room maintained under similar environmental conditions. Subjects were administered a single oral dose of test compound by gavage and allowed to recover in their home cage prior to euthanasia at $6 \mathrm{~h}$ (dose-response studies) or 1, 3, 6 or $9 \mathrm{~h}$ (time course studies). Subjects were removed to an adjoining suite with a separate HVAC system for euthanasia by decapitation. Whole brains were rapidly removed onto a cold plate $\left(4^{\circ} \mathrm{C}\right)$. Frontal cortex was dissected and frozen on a bed of dry ice in less than 3 minutes and then stored at $-80^{\circ} \mathrm{C}$ until use.

\section{RNA Extraction}

Cortical samples were homogenized in $1 \mathrm{~mL}$ of TRI Reagent (Molecular Research Center, Inc., Cincinnati, $\mathrm{OH}$ ) per 50-100 mg of tissue using a Polytron ${ }^{\circledR}$ PT-K homogenizer (Kinematica, Lucerne, Switzerland) and total RNA was isolated per manufacturer's instructions. Total RNA pellets suspended in DEPC-treated $\mathrm{H}_{2} \mathrm{O}$ were then subject to DNase I treatment and re-extracted with acid:phenol chloroform, $\mathrm{pH}=4.7$ (Ambion Inc., Austin, TX) and chloroform according to manufacturer's protocol and re-suspended in DEPC-treated $\mathrm{H}_{2} \mathrm{O}$ until use. The total RNA concentration of each sample was determined (absorbance @ 260 nm) on a Beckman-Coulter DU ${ }^{\circledR} 800$ spectrophotometer (Fullerton, CA) and adjusted to $1.0 \mu \mathrm{g} / \mu \mathrm{L}$ prior to sample storage at $-80^{\circ} \mathrm{C}$. The ratio of absorbance values at $260 \mathrm{~nm}$ and $280 \mathrm{~nm}$ (Ab 260/280) was used to assess purity of total RNA samples and a cut-off of $>1.6$ was used (greater than $85 \%$ of the samples were $>1.7$ ). Preliminary PCR experiments using primers for rat $\beta$-actin genomic DNA (outlined in [37]) demonstrated that the above protocol adequately prevents genomic DNA contamination of total RNA samples (data not shown). RNA integrity of each sample was determined using an Agilent 2100 Bioanalyzer and RNA 6000 Nano LabChip Kit

Table I: Group sizes of cohorts used in this study.

\begin{tabular}{|c|c|c|c|c|c|c|c|c|}
\hline \multirow[b]{2}{*}{ Dose (mg/kg): } & \multirow[b]{2}{*}{ Vehicle } & \multicolumn{4}{|c|}{ Permethrin } & \multicolumn{3}{|c|}{ Deltamethrin } \\
\hline & & 1.0 & 10.0 & 40.0 & 100.0 & 0.3 & 1.0 & 3.0 \\
\hline EDL: & Control & $<$ NOAEL & NOAEL & $\mathrm{ED}_{30}$ & $\mathbf{E D}_{50}$ & $<$ NOAEL & NOAEL & $\mathbf{E D}_{30}$ \\
\hline \multicolumn{9}{|c|}{ Microarray Dose Response a } \\
\hline Cohort I & 6 & 3 & 3 & & 3 & 3 & 3 & 3 \\
\hline Cohort 2 & 6 & 5 & 5 & & 5 & 5 & 5 & 5 \\
\hline \multicolumn{9}{|c|}{ qRT-PCR Dose-Response b } \\
\hline \multirow[t]{2}{*}{ Cohort 3} & 7 & 7 & 7 & 7 & 7 & & & \\
\hline & 7 & & & & & 7 & 7 & 7 \\
\hline \multicolumn{9}{|c|}{ qRT-PCR Time Course c } \\
\hline \multirow[t]{2}{*}{ Cohort 4} & 84 & & & & 84 & & & \\
\hline & 84 & & & & & & & 84 \\
\hline
\end{tabular}

\footnotetext{
a Microarray data from Cohorts I \& 2 were combined $(n=8 /$ treatment group) with control values from cohorts I \& $2(n=12)$ for dose-response analysis of permethrin and deltamethrin mediated effects, respectively. b Test animals in Cohort 3 were split into two dose-response studies for permethrin and deltamethrin, respectively, for qRT-PCR confirmation of gene expression changes observed during the microarray study. ${ }^{c}$ Test animals in Cohort 4 were used for qRT-PCR time course studies. Four time points ( $1,3,6,9$ hours: $n=8 /$ treatment group) per compound with time matched controls $(n=8 /$ control group). NOAEL $=$ no observable adverse effect level; $<$ NOAEL $=$ less than no observable adverse effect level.
} 
(Waldbron, Germany) according to manufacturer's instructions. All samples used in microarray and qRT-PCR experiments had a RNA Integrity Number (RIN) > 8.0 (data not shown). Aliquots of each RNA sample $(1 \mu \mathrm{g} / \mu \mathrm{L}$ for microarray hybridization or $25 \mathrm{ng} / \mu \mathrm{L}$ for qRT-PCR assays) were stored at $-80^{\circ} \mathrm{C}$ until use.

\section{Microarray sample preparation and data collection}

All protocols for microarray sample preparation (except total RNA extraction, as above), Affymetrix Rat Genome 2302.0 GeneChip $^{\circledast}$ hybridization, array scanning and data collection were performed by Expression Analysis, Inc., (Durham, NC) according to standard Affymetrix protocols. Synthesis and clean-up of biotin-labeled cRNA was performed using a BioArray ${ }^{\mathrm{TM}}$ High Yield $^{\mathrm{TM}}$ RNA transcript labeling kit (Enzo Life Sciences, Farmingdale, NY) and Qiagen RNeasy spin columns (Spoorstraat, Netherlands), respectively, according to manufacturer's instructions. Hybridizations were performed in an Affymetrix Hybridization Oven 640. Washes were performed on an Affymetrix Fluidics Station 450 using the EukGE-WS2v4-450 fluidics script. GeneChips ${ }^{\circledast}$ were scanned using an Affymetrix GeneChip ${ }^{\circledR} 3000$ Scanner with the GCOS v1.2 software package. Target intensity was set to a value of 500 with all other scanning parameters set at the factory defaults. The $31 / 5$ ' ratios for GAPDH and $\beta$-actin internal controls genes ranged between $0.93-1.11$ and $1.2-2.01$, respectively for all samples, indicating that degradation of RNA did not occur. The intensity of hybridization controls (BioB, BioC, BioD and Cre) increased linearly on all arrays. Gene expression profiles for this experiment have been archived in the NCBI Gene Expression Omnibus (GEO) repository with the series accession number GSE7955.

\section{Microarray Data Analysis}

Expression summaries were calculated using RMAExpress ${ }^{\odot}$ v4.7 (University of California at Berkeley). Consistent with previous reports, Robust Multiarray Average (RMA) [38] provided less within group variation in expression summary values as compared to GeneChip ${ }^{\circledR}$ Operating Software v1.2 (GCOS) [39] (see Additional file 1).

Analysis of dose-response relationships were performed using Significance Analysis of Microarrays (SAM, version 2.21) [34], with the quantitative/linear regression modeling component [40]. In addition to identifying doseresponsive genes, SAM provides permutation-based estimates of the false-discovery rate (FDR) associated with lists of genes for which the null hypothesis is rejected. The SAM statistic $\left(d_{i}\right)$ penalizes lowly expressed genes, and is most powerful when the dose-response function is nearly linear in the range examined. To potentially increase power and account for non-linearity in dose-response relationships, the SAM analyses were supplemented by penalized isotonic regression (PIR) according to the method of Hu et al. (2005) [35] which was specifically designed for microarray analysis. Similar to SAM, PIR penalizes lowly expressed genes and provides a permutation-based estimate of the false discovery rate. In contrast to SAM, PIR allows for the dose-response relationship to be nonlinear, but assumes the relationship is increasing or decreasing as a function of increasing dose, and not the reverse direction. This method results in a score (the $M_{i}{ }^{-}$ statistic) for each probe set that quantifies the evidence for an increasing or decreasing dose-response relationship.

To insure that the rigorously conservative, permutationbased approaches for controlling Type I error did not exclude true positive probe sets with dose-dependent increases or decreases in expression, an additional analysis was conducted with each regression model. Empirical $p$-values from the PIR analysis or SAM analysis were used to filter out probe sets with no apparent dose-related changes in expression (threshold $p$-value $<0.01$ ). The reduced group of probe sets were then analyzed using a one-way analysis of variance (ANOVA) followed by a Benjamini-Hochberg correction for control of multiple comparisons. Dose was used as the independent factor. Probe sets meeting the Benjamini-Hochberg correction at FDR < 0.05 were included in the gene lists of interest for each compound, analysis of dose thresholds for transcriptional changes and the comparison of effects between compounds. For probe sets that passed the one-way ANOVA significance threshold, a post-hoc Dunnett's multiplecomparison mean contrast test was performed comparing the means of the respective dose groups to the mean of the control group [41]. Regression analyses were performed using $\mathrm{R}^{\oplus}$ version 2.3.0 statistical computing analysis software. Dunnett's tests were performed using SAS v8.1 (SAS Institute, Inc., Cary, NC).

\section{Quantitative real-time $R T-P C R$}

In selecting candidates for qRT-PCR confirmation, preference was given to probe sets highly ranked by the penalized regression methods and corresponding to transcripts with known protein-coding RefSeq accession numbers (Tables 2 \&3). qRT-PCR for each transcript of interest was performed using TaqMan ${ }^{\circledR}$ One-Step RT-PCR Master Mix Reagent Kits and TaqMan ${ }^{\circledR}$ Gene Expression Assays on an ABI 7900HT Sequence Detection System (Applied Biosystems, Foster City, CA) according to manufacturer's instructions and using a 384 well plate format. Each sample was measured in triplicate for each transcript of interest and an internal reference gene. Reaction plates were maintained at $5^{\circ} \mathrm{C}$ during the loading procedure. Reactions were incubated at $48^{\circ} \mathrm{C}$ for $45 \mathrm{~min}$ followed by incubation at $95^{\circ} \mathrm{C}$ for $10 \mathrm{~min}$ and 40 cycles of $94^{\circ} \mathrm{C}$ for $25 \mathrm{sec}$ followed by $60^{\circ} \mathrm{C}$ for $1 \mathrm{~min}$. qRT-PCR assays were designed via the Applied Biosystems (ABI) primer/probe selection algorithm and bioinformatics pipeline [42]. 
Table 2: Probe sets identified as dose-responsive for deltamethrin.

\begin{tabular}{|c|c|c|c|c|c|c|c|c|}
\hline \multirow[b]{2}{*}{ Affymetrix Probe Set I.D. } & \multirow[b]{2}{*}{ Gene Symbol } & \multicolumn{3}{|c|}{ Linear Regression (SAM) } & \multicolumn{3}{|c|}{ Isotonic Regression (PIR) } & \multirow{2}{*}{$\begin{array}{c}\text { ANOVA } \\
p \text {-value }\end{array}$} \\
\hline & & $d_{i}$ & $p$-value & $q$-value & $M_{i}$ & $p$-value & $q$-value & \\
\hline |37|363_at & GpdI** & 5.63 & 0.0000 & 0.00 & 2.34 & 0.0000 & 0.24 & 0.0032 \\
\hline |38890|_at & $F k b p 5 I^{* *}$ & 5.46 & 0.0000 & 0.00 & 2.21 & 0.0000 & 0.42 & 0.0051 \\
\hline 1367577_at & Hsp27** & 4.60 & 0.0001 & 0.00 & 1.90 & 0.0002 & 0.97 & 0.0195 \\
\hline 1369560_at & GpdI** & 4.53 & 0.0001 & 0.00 & 1.91 & 0.0002 & 1.00 & 0.0134 \\
\hline 1368064_a_at & $D d c^{* *}$ & -4.35 & 0.0001 & 0.14 & -1.95 & 0.0002 & 1.00 & 0.0195 \\
\hline 1391229_at & Camk / g*** & 4.22 & 0.0002 & 0.00 & 2.11 & 0.0000 & 0.51 & 0.0063 \\
\hline |3806||_at & Fkbp5I** & 3.90 & 0.0004 & 0.11 & 1.62 & 0.0012 & 1.00 & 0.0276 \\
\hline 1369303_at & Crh & 3.62 & 0.0009 & 0.11 & 1.73 & 0.0006 & 1.00 & 0.0276 \\
\hline |38827|_at & LOC6894I5 & 3.48 & 0.0013 & 0.19 & 1.44 & 0.0037 & 1.00 & 0.0300 \\
\hline 1370989_at & Ret & 3.38 & 0.0017 & 0.19 & 1.49 & 0.0028 & 1.00 & 0.0300 \\
\hline |370026_at & Cryab & 3.28 & 0.0022 & 0.29 & 1.46 & 0.0032 & 1.00 & 0.0364 \\
\hline 1374626_at & $\operatorname{Lrgl}$ & 3.23 & 0.0025 & 0.33 & 1.45 & 0.0036 & 1.00 & 0.0323 \\
\hline 1376709_at & Slc39a8 & -3.07 & 0.0038 & 0.14 & -1.49 & 0.0026 & 1.00 & 0.0364 \\
\hline 1368650_at & KIfIO & -3.07 & 0.0038 & 0.14 & -1.30 & 0.0077 & 1.00 & 0.0356 \\
\hline 1380329_at & Tmem 10 & -3.03 & 0.0041 & 0.14 & -1.28 & 0.0086 & 1.00 & 0.0496 \\
\hline 1372564_at & Ets2 & 3.03 & 0.0042 & 0.51 & 1.41 & 0.0045 & 1.00 & 0.0396 \\
\hline 1389507_at & Nedd4I & 2.97 & 0.0048 & 0.51 & 1.42 & 0.0043 & 1.00 & 0.0306 \\
\hline |375|38_at & Timp3 & 2.92 & 0.0054 & 0.56 & 1.22 & 0.0134 & 1.00 & 0.0319 \\
\hline 1370530_a_at & PIdI & -2.81 & 0.0071 & 0.14 & -1.34 & 0.0062 & 1.00 & 0.0493 \\
\hline |385778_at & Siat7E & 2.79 & 0.0075 & 1.15 & 1.38 & 0.0055 & 1.00 & 0.0276 \\
\hline 1395986_at & Slit2 & -2.78 & 0.0077 & 0.14 & -1.27 & 0.0094 & 1.00 & 0.0419 \\
\hline 1369973_at & $X d h$ & 2.76 & 0.0080 & 1.15 & 1.18 & 0.0167 & 1.00 & 0.0472 \\
\hline 1368438_at & Pdel0a & 2.70 & 0.0094 & 1.16 & 1.11 & 0.0255 & 1.00 & 0.0496 \\
\hline 1387260_at & KIf4 & -2.69 & 0.0096 & 0.14 & -1.49 & 0.0026 & 1.00 & 0.0429 \\
\hline 1372356_at & Usp54 & 2.69 & 0.0097 & 1.16 & 1.12 & 0.0240 & 1.00 & 0.0442 \\
\hline |37|442_at & Hyoul & 2.68 & 0.0099 & 1.16 & 1.03 & 0.0384 & 1.00 & 0.0467 \\
\hline 1375296_at & LOC684097 & 2.66 & 0.0105 & 1.16 & 1.40 & 0.0047 & 1.00 & 0.0427 \\
\hline 1398899_at & Polr2c & 2.64 & 0.0110 & 1.16 & 1.67 & 0.0009 & 1.00 & 0.0195 \\
\hline |3775|8_at & Camk I g*** & 2.59 & 0.0123 & 1.16 & 1.29 & 0.0090 & 1.00 & 0.0315 \\
\hline 1372090_at & Max & 2.53 & 0.0143 & 1.16 & 1.31 & 0.0080 & 1.00 & 0.0306 \\
\hline |38|557_at & Gnal4 & 2.35 & 0.0216 & 1.16 & 1.29 & 0.0087 & 1.00 & 0.0442 \\
\hline 1398373_at & B3galt3 & 2.29 & 0.0248 & 1.16 & 1.29 & 0.0091 & 1.00 & 0.0396 \\
\hline 1372037_at & Pdlm7 & 2.18 & 0.0319 & 1.16 & 1.28 & 0.0098 & 1.00 & 0.0351 \\
\hline 1382/12_at & LOC682926 & -2.16 & 0.0333 & 1.15 & -1.26 & 0.0096 & 1.00 & 0.0344 \\
\hline 1375752_at & Bves & -1.96 & 0.0519 & 1.15 & $-1.4 \mid$ & 0.0042 & 1.00 & 0.0376 \\
\hline 1370869_at & Bcat I & 1.92 & 0.0561 & 1.16 & 1.28 & 0.0096 & 1.00 & 0.0345 \\
\hline 1367706_at & Vdacl & 1.74 & 0.0820 & 1.16 & 1.29 & 0.0090 & 1.00 & 0.0295 \\
\hline
\end{tabular}

** = genes examined by qRT-PCR. Positive SAM $d_{i}$ or PIR $M_{i}$ scores denote upregulated probe sets. Negative SAM $d_{i}$ or PIR $M_{i}$ scores denote downregulated probe sets. A full list of probe sets altered by deltamethrin exposure, including predicted protein coding sequences and expressed sequence tags is given in Additional file 3.

Amplification efficiencies for each assay was calculated as previously described using a serial dilution of pooled total RNA from rat frontal cortex [43]. Assay identification numbers, context sequences, amplicon lengths and calculated amplification efficiencies are listed in Additional file 2 .

qRT-PCR data from deltamethrin and permethrin doseresponse and time course studies were analyzed according to the $2-\Delta \Delta \mathrm{C}_{\mathrm{T}}$ method as described by Livak and Schmittgen (2001) [44]. $\beta$-actin expression did not change as a function of time or dose for either compound (data not shown) and was used at the internal reference for all $2-\Delta \Delta \mathrm{C}_{\mathrm{T}}$ calculations. Data are expressed as $2-\Delta \Delta \mathrm{C}_{\mathrm{T}} \pm$ standard error
(SE) which is an approximation of fold-change from the calibrator group (i.e. vehicle control). For dose-response studies (Table 4), the mean $\Delta \Delta^{\mathrm{C}}$ of vehicle treated controls were used as the $2^{-\Delta \Delta \mathrm{C}_{\mathrm{T}}}$ calibrator [44]. For time course studies, the mean $\Delta \Delta \mathrm{C}_{\mathrm{T}}$ of vehicle treated controls were used as the $2^{-\Delta \Delta C_{T}}$ calibrator within each timematched treatment group.

Data from Wolansky et al. (2006) [33] were used to assign equipotent dose-levels (EDL) to the administered doses used in the present study to provide a comparative dosemetric between the two test compounds (see Table 1). Statistical analysis of qRT-PCR dose response data was performed using a two-way ANOVA with compound and 
Table 3: Probe sets identified as dose-responsive for permethrin.

\begin{tabular}{|c|c|c|c|c|c|c|c|c|}
\hline \multirow[b]{2}{*}{ Affymetrix Probe Set I.D. } & \multirow[b]{2}{*}{ Gene Symbol } & \multicolumn{3}{|c|}{ Linear Regression (SAM) } & \multicolumn{3}{|c|}{ Isotonic Regression (PIR) } & \multirow{2}{*}{$\begin{array}{c}\text { ANOVA } \\
p \text {-value }\end{array}$} \\
\hline & & $d_{i}$ & $p$-value & $q$-value & $M_{i}$ & $p$-value & $q$-value & \\
\hline |369303_at & $\mathrm{Crh}$ & 4.26 & 0.0001 & 0.00 & 1.92 & 0.0003 & 1.00 & 0.0113 \\
\hline |368677_at & $B d n f * *$ & 3.85 & 0.0003 & 0.00 & 1.52 & 0.0025 & 1.00 & 0.0170 \\
\hline |3704|2_at & Slc40al & -3.50 & 0.0006 & 0.18 & -1.70 & 0.0016 & 1.00 & 0.0050 \\
\hline |3704|5_at & Rassf5** & 3.37 & 0.0008 & 0.12 & 1.85 & 0.0004 & 1.00 & 0.0170 \\
\hline 1375043_at & c-fos** & 3.23 & 0.0012 & 0.18 & $1.4 \mid$ & 0.0045 & 1.00 & 0.0170 \\
\hline |39599|_at & Rimbp2 & 3.11 & 0.0016 & 0.28 & 1.39 & 0.0050 & 1.00 & 0.0400 \\
\hline 1388583_at & $C x c 1 / 2$ & 2.92 & 0.0027 & 0.42 & 1.36 & 0.0057 & 1.00 & 0.0477 \\
\hline |36832|_at & Egrl** & 2.87 & 0.0030 & 0.50 & 1.21 & 0.0132 & 1.00 & 0.0230 \\
\hline 1369067_at & $\mathrm{Nr} 4 a 3$ & 2.77 & 0.0040 & 0.55 & 1.15 & 0.0187 & 1.00 & 0.0270 \\
\hline 1387025_at & Dynclil & 2.76 & 0.0041 & 0.55 & 1.29 & 0.0085 & 1.00 & 0.0208 \\
\hline |38|557_at & Gnal4 & 2.67 & 0.0052 & 0.61 & 1.87 & 0.0004 & 1.00 & 0.0176 \\
\hline |387024_at & Dusp6 & 2.59 & 0.0064 & 0.75 & 1.01 & 0.0398 & 1.00 & 0.0230 \\
\hline |3889||_at & Prim2 & 2.50 & 0.0082 & 0.79 & 1.45 & 0.0036 & 1.00 & 0.0408 \\
\hline 1385778_at & Siat7E & 2.36 & 0.0116 & 0.79 & 1.43 & 0.0041 & 1.00 & 0.0305 \\
\hline 1395272_at & LOC682937 & -1.88 & 0.0394 & 0.69 & -1.33 & 0.0084 & 1.00 & 0.0305 \\
\hline 1367652_at & Igfbp3 & 1.38 & 0.1190 & 0.79 & 1.35 & 0.0063 & 1.00 & 0.0358 \\
\hline 1389090_at & Wrnipl & 1.32 & 0.1319 & 0.79 & 1.30 & 0.0079 & 1.00 & 0.0170 \\
\hline 1376602_a_at & $\mathrm{Fbxo22}$ & 0.89 & 0.2974 & 1.32 & 1.27 & 0.0096 & 1.00 & 0.0186 \\
\hline 139130|_at & LOC682355 & 0.51 & 0.5404 & 1.32 & 1.35 & 0.0062 & 1.00 & 0.0305 \\
\hline
\end{tabular}

** = genes examined by qRT-PCR. Positive SAM $d_{i}$ or PIR $M_{i}$ scores denote upregulated probe sets. Negative SAM $d_{i}$ or PIR $M_{i}$ scores denote downregulated probe sets. A full list of probe sets altered by deltamethrin exposure, including predicted protein coding sequences and expressed sequence tags is given in Additional file 4.

equipotent dose level (EDL) as independent variables and $2-\Delta \Delta \mathrm{C}_{\mathrm{T}}$ as the dependent variable followed by Dunnett's mean contrast test. Transcripts with a significant compound by EDL interaction were further analyzed using a one-way ANOVA with dose as the independent variable followed by Dunnett's mean contrast test. Statistical analysis of time course data was performed using a two-way ANOVA with time and treatment as independent variables and $2-\Delta \Delta \mathrm{C}_{\mathrm{T}}$ as the dependent variable. Transcripts with a significant time* treatment interaction $(p<0.05)$ were additionally analyzed with a one-way ANOVA at each time point with treatment as the independent variable ( $p$ $<0.05)$.

\section{Significance Analysis of Function and Expression (SAFE)}

The SAFE method was used to identify pathways/functional categories whose genes are coordinately regulated in a dose-dependent manner [36]. SAFE is similar to other pathway enrichment procedures (e.g. DAVID) [45], but accounts for correlation in gene expression within pathways using array permutation to rigorously control error rates. SAFE and accompanying array annotation were loaded from Bioconductor v.1.8 [46]. SAFE tests for enrichment of significant dose-response relationships for genes within each pathway. Following calculation of linear regression dose-response $p$-values for each gene, only genes with a nominal $p$-value $<0.05$ were used to form the gene list to which the enrichment analysis was performed. SAFE [47] enables the user to define a pathway enrichment statistic and a Pearson test of binomial proportions was then implemented [48]. The Pearson statistics is similar to Fisher's exact test commonly employed in pathway enrichment testing (GSEA) [49], but does not consider the number of significant genes to have been fixed $a$ priori [50]. 10,000 permutations of dose levels were used by SAFE to assess the significance of the entire procedure, using the Yekutieli and Benjamini (1999) procedure to control the FDR while accounting for the multiple pathways/categories [51]. All categories with an estimated FDR $<0.1$ are reported in Table 5.

\section{Combining pathway evidence for the two pyrethroids}

One aim of using the SAFE statistical methods in this study was to identify gene categories showing enrichment for dose-responsiveness for both permethrin and deltamethrin. The Fisher combined p-value method allows accrual of evidence across multiple hypotheses, and thus is ideal for testing combined evidence for enrichment of each pathway for both chemicals [52]. Under the null hypothesis that neither chemical shows enrichment for the pathway, each of the two $p$-values is uniform $[0,1]$, and the Fisher statistic

$$
S=-2\left(\ln \left(p_{\text {delta }}\right)+\ln \left(p_{\text {norm }}\right)\right)
$$

is distributed as $\chi_{2}^{2}$. The Fisher approach has favorable optimality properties [53] and results in a new (combined) $p$-value for each pathway. For the multiple pathways tested, the Benjamini-Hochberg (1995) method was 
Table 4: qRT-PCR confirmation of transcripts identified as dose-responsive.

\begin{tabular}{|c|c|c|c|c|c|c|}
\hline & Deltamethrin & & & Permethrin & & \\
\hline Camklga & $q R T-P C R$ & |39|229_at & |3775/8_at & $q R T-P C R$ & 1391229_at & |3775|8_at \\
\hline Control & $1.03 \pm 0.10$ & $1.00 \pm 0 . \overline{0} 4$ & $1.00 \pm 0.05$ & $1.04 \pm 0.13$ & $1.00 \pm 0 . \overline{0} 4$ & $1.00 \pm 0.05$ \\
\hline$<$ NOAEL & $1.23 \pm 0.18$ & $1.10 \pm 0.03$ & $1.07 \pm 0.08$ & $1.05 \pm 0.14$ & $1.16 \pm 0.10$ & $1.20 \pm 0.13$ \\
\hline NOAEL & $1.40 \pm 0.18$ & $1.26 \pm 0.07$ & $1.31 \pm 0.06$ & $1.97 \pm 0.28 *$ & $1.09 \pm 0.05$ & $1.09 \pm 0.09$ \\
\hline $\mathrm{ED}_{30}$ & $1.57 \pm 0.14^{*}$ & $1.31 \pm 0.06$ & $1.39 \pm 0.06$ & $1.76 \pm 0.32^{*}$ & & \\
\hline $\mathrm{ED}_{50}$ & & & & $1.72 \pm 0.30 *$ & $1.25 \pm 0.09$ & $1.45 \pm 0.17$ \\
\hline Ddc ${ }^{a}$ & qRT-PCR & 1368064 a at & & qRT-PCR & 1368064 a at & \\
\hline Control & $1.01 \pm 0.06$ & $1.00 \pm 0.03$ & & $1.04 \pm 0.12$ & $1.00 \pm 0.03$ & \\
\hline$<$ NOAEL & $0.79 \pm 0.06$ & $0.96 \pm 0.04$ & & $0.97 \pm 0.10$ & $1.04 \pm 0.04$ & \\
\hline NOAEL & $0.89 \pm 0.07$ & $0.90 \pm 0.05$ & & $0.91 \pm 0.10$ & $1.01 \pm 0.04$ & \\
\hline $\mathrm{ED}_{30}$ & $0.70 \pm 0.05^{*}$ & $0.80 \pm 0.03$ & & $0.81 \pm 0.11^{*}$ & & \\
\hline $\mathrm{ED}_{50}$ & & & & $0.71 \pm 0.09 *$ & $1.00 \pm 0.05$ & \\
\hline GpdIb & $q R T-P C R$ & |37/363_at & 1369560_at & $q R T-P C R$ & |37/363_at & 1369560_at \\
\hline Control & $1.06 \pm 0.13$ & $1.00 \pm 0.11$ & $1.00 \pm 0.08$ & $1.04 \pm 0.14$ & $1.00 \pm 0.11$ & $1.00 \pm 0.08$ \\
\hline$<$ NOAEL & $1.16 \pm 0.13$ & $0.88 \pm 0.07$ & $0.88 \pm 0.05$ & $0.94 \pm 0.07$ & $1.03 \pm 0.10$ & $0.98 \pm 0.09$ \\
\hline NOAEL & $1.04 \pm 0.12$ & $1.42 \pm 0.17$ & $1.25 \pm 0.13$ & $0.97 \pm 0.06$ & $1.03 \pm 0.09$ & $0.95 \pm 0.10$ \\
\hline $\mathrm{ED}_{30}$ & $2.04 \pm 0.28^{*}$ & $1.94 \pm 0.19$ & $1.55 \pm 0.14$ & $1.24 \pm 0.15$ & & \\
\hline $\mathrm{ED}_{50}$ & & & & $1.23 \pm 0.13$ & $1.19 \pm 0.18$ & $1.12 \pm 0.16$ \\
\hline Fkbp5I b & $q R T-P C R$ & |38890I_at & |3806| I_at & $q R T-P C R$ & |38890I_at & |3806|I_at \\
\hline Control & $1.01 \pm 0.06$ & $1.00 \pm 0.05$ & $1.00 \pm 0 . \overline{0} 4$ & $1.02 \pm 0.09$ & $1.00 \pm 0.05$ & $1.00 \pm 0.04$ \\
\hline$<$ NOAEL & $0.92 \pm 0.06$ & $1.00 \pm 0.03$ & $1.04 \pm 0.07$ & $1.03 \pm 0.09$ & $0.92 \pm 0.05$ & $0.96 \pm 0.07$ \\
\hline NOAEL & $1.02 \pm 0.07$ & $1.17 \pm 0.05$ & $1.16 \pm 0.08$ & $1.00 \pm 0.06$ & $1.06 \pm 0.03$ & $0.99 \pm 0.06$ \\
\hline $\mathrm{ED}_{30}$ & $1.52 \pm 0.14^{*}$ & $1.4 I \pm 0.09$ & $1.35 \pm 0.10$ & $0.95 \pm 0.07$ & & \\
\hline $\mathrm{ED}_{50}$ & & & & $1.03 \pm 0.12$ & $1.07 \pm 0.05$ & $1.07 \pm 0.09$ \\
\hline$c-f_{0} c$ & $q R T-P C R$ & |375043_at & & $q R T-P C R$ & |375043_at & \\
\hline Control & $1.19 \pm 0.27$ & $1.00 \pm 0.16$ & & $1.09 \pm 0.21$ & $1.00 \pm 0.16$ & \\
\hline$<$ NOAEL & $0.63 \pm 0.14$ & $1.01 \pm 0.31$ & & $1.49 \pm 0.25$ & $0.54 \pm 0.07$ & \\
\hline NOAEL & $1.09 \pm 0.43$ & $0.72 \pm 0.12$ & & $1.30 \pm 0.22$ & $0.57 \pm 0.08$ & \\
\hline $\mathrm{ED}_{30}$ & $0.54 \pm 0.08 *$ & $0.69 \pm 0.06$ & & $0.91 \pm 0.11$ & & \\
\hline $\mathrm{ED}_{50}$ & & & & $1.25 \pm 0.27$ & $1.56 \pm 0.34$ & \\
\hline Egrl c & $q R T-P C R$ & I36832I_at & & $q R T-P C R$ & |36832I_at & \\
\hline Control & $1.04 \pm 0.12$ & $1.00 \pm 0.08$ & & $1.01 \pm 0.07$ & $1.00 \pm 0.16$ & \\
\hline$<$ NOAEL & $0.81 \pm 0.05$ & $0.93 \pm 0.09$ & & $1.10 \pm 0.10$ & $0.77 \pm 0.02$ & \\
\hline NOAEL & $0.90 \pm 0.16$ & $0.95 \pm 0.08$ & & $1.10 \pm 0.11$ & $0.89 \pm 0.09$ & \\
\hline $\mathrm{ED}_{30}$ & $0.87 \pm 0.07$ & $0.98 \pm 0.06$ & & $1.09 \pm 0.08$ & & \\
\hline $\mathrm{ED}_{50}$ & & & & $1.12 \pm 0.10$ & $1.19 \pm 0.08$ & \\
\hline
\end{tabular}

Values in normal type-set are 2- $\Delta \Delta \mathrm{CT}( \pm \mathrm{SE})$ from qRT-PCR Cohort 3. For comparison, values in italics are fold-change from control $( \pm \mathrm{SE})$ for microarray probe sets (Cohorts I \& 2). Groups for statistical analysis are given in Table I. Equipotent dose groups are based on Wolansky et al (2006). Main effects in two-way ANOVA: a = EDL $(p<0.05)$, b = COMPOUND*EDL $(p<0.05)$ and DOSE $(p<0.05)$ for deltamethrin only in oneway ANOVA, $c=$ COMPOUND $(p<0.05)$. * = Significance difference from control in a Dunnett's mean contrast test $(p<0.05)$.

applied to control the false discovery rate $(F D R<0.1)$ [54].

Fisher's statistic can be asymmetrically sensitive to very small $p$-values for a single chemical, even if the results for the other chemical are not significant. Thus, among pathways with a significant Fisher statistic, the focus was placed on those which showed SAFE $p$-values $<0.05$ for both chemicals.

\section{Cell culture and treatment}

Cortical cultures containing neurons and glia were prepared from neocortices of newborn rat pups according to the protocol used by Chandler et al. (1993) with modifications [55]. Neocortices were harvested under sterile conditions in a buffer solution containing $137 \mathrm{mM} \mathrm{NaCl}, 5$ $\mathrm{mM} \mathrm{KCl}, 170 \mu \mathrm{M} \mathrm{Na}_{2} \mathrm{HPO}_{4}, 205 \mu \mathrm{M} \mathrm{KH}_{2} \mathrm{PO}_{4}, 5 \mathrm{mM}$ glucose, $59 \mathrm{mM}$ sucrose, $100 \mathrm{U} / \mathrm{ml}$ penicillin and $0.1 \mathrm{mg} / \mathrm{ml}$ streptomycin, $\mathrm{pH}$ 7.4. The cortices were minced with scissors and digested using $0.25 \%$ trypsin for 5 minutes, then with addition of $0.016 \%$ DNase for a further 5 minutes at 
Table 5: Significant Analysis of Function and Expression (SAFE) results.

\begin{tabular}{|c|c|c|c|}
\hline \multicolumn{4}{|c|}{ Commonly enriched gene categories for both permethrin and deltamethrin ${ }^{a}$} \\
\hline Category I.D. and name & size $^{b}$ & DLT p-value & PERM p-value \\
\hline \multicolumn{4}{|l|}{ GO Biological Process } \\
\hline GO:0048754, 'branching morophogenesis of a tube' & 66 & 0.0171 & 2.00E-04 \\
\hline GO:0001763, 'morphogenesis of a branching structure' & 67 & 0.0172 & 2.00E-04 \\
\hline GO:0007I62, 'negative regulation of cell adhesion' & 27 & 0.0175 & 0.0025 \\
\hline GO:0015718, 'monocarboxylic acid transport' & 30 & 0.0051 & 0.0125 \\
\hline GO:0007498, 'mesoderm development' & 57 & 0.0105 & 0.0067 \\
\hline \multicolumn{4}{|l|}{ GO Cellular Component } \\
\hline GO:0005954, ' $\mathrm{Ca}^{+2}$ and calmodulin-dependent protein kinase complex' & 25 & 0.0053 & 0.0146 \\
\hline \multicolumn{4}{|l|}{ GO Molecular Function } \\
\hline GO:0046915, 'transition metal ion transporter activity' & 44 & 0.0026 & 0.0348 \\
\hline \multicolumn{4}{|c|}{ Enriched gene categories identified by SAFE. } \\
\hline Category I.D. and name & size $^{b}$ & $p$-value & \\
\hline \multicolumn{4}{|l|}{ Deltamethrin } \\
\hline \multicolumn{4}{|l|}{ KEGG Pathway } \\
\hline KEGG:00564, 'Glycerophospholipid metabolism' & 73 & 0.0404 & \\
\hline KEGG:00400, 'Phenylalanine, tyrosine and tryptophan biosynthesis & 12 & 0.0928 & \\
\hline \multicolumn{4}{|l|}{ Permethrin } \\
\hline \multicolumn{4}{|l|}{ GO Biological Process } \\
\hline GO:0048754, 'branching morphogenesis of a tube' & 66 & 0.0349 & \\
\hline GO:0001763, 'morphogenesis of a branching structure' & 67 & 0.0349 & \\
\hline GO:000I569, 'patterning of blood vessels' & 31 & 0.0406 & \\
\hline GO:0009880, 'embryonic pattern specification' & 49 & 0.0554 & \\
\hline GO:0045655, 'regulation of monocyte differentiation' & 32 & 0.0932 & \\
\hline
\end{tabular}

a GO catergories or KEGG pathways with $p<0.05$ for both test compounds using Fisher's combined $p$-value method to test for joint enrichment in the SAFE procedure. ${ }^{b}$ number of Affymetrix probe sets included in GO category or KEGG pathway groupings. ${ }^{c} \mathrm{GO}$ categories or KEGG pathways with an adjusted $p<0.1$ for SAFE method. 700 GO-BP (biological processes), 142 GO-CC (cellular component), 307 GO-MF (molecular function) and 126 KEGG pathways were examined.

$37^{\circ} \mathrm{C}$ and mixed at $30 \mathrm{rpm}$. The cortices were centrifuged $(400 \times \mathrm{g}, 1600 \mathrm{rpm})$ for 5 minutes at room temperature, the supernatant was aspirated and the tissue pellet was resuspended in Gibco ${ }^{\circledR}$ DMEM/GlutaMAX-1 (Invitrogen Corp, Carlsbad, CA) containing 10 mM HEPES, 100 U/ml penicillin, $0.1 \mathrm{mg} / \mathrm{ml}$ streptomycin and $10 \%$ horse serum, $\mathrm{pH}=7.4$. The tissue was dissociated by trituration and filtered through a $100-\mu \mathrm{m}$ Nitex screen. Cells were plated at a density of 50,000 cells/well in 96-well polystyrene plates (Corning, Inc., Corning, NY) that had been pre-coated with poly-L-lysine. Cells were incubated at $37^{\circ} \mathrm{C}$ in a humidified atmosphere of 5\% $\mathrm{CO}_{2}$ and $95 \%$ air.

Multi-compartment pharmacokinetic models for the disposition of deltamethrin and permethrin were used to predict tissue concentrations of deltamethrin and permethrin in the brain at $6 \mathrm{~h}$ following the acute administered doses used in this study [56,57]. Predictions are listed in Table 6 . These estimated brain concentrations were then used to select nominal media concentrations of pyrethroids for use in the functional neurite morphogenesis cell model.

For in vitro exposure of cells, pyrethroids were prepared in DMSO using semi-logarithmic serial dilutions of concentrated stock solutions to yield final chemical concentration ranges of $0.001-0.03 \mu \mathrm{M}$ and $0.01-3 \mu \mathrm{M}$ for deltamethrin and permethrin, respectively. The final DMSO concentration in the cortical media was $0.1 \%$. Chemicals were added to the cells 2 hours after plating to ensure the cells adhered to the poly-L-lysine and incubated for a 96-hour exposure period.

\section{Evaluation of neurite outgrowth and cell viability}

Immunocytochemical staining with a Neurite Outgrowth Hitkit (Thermo-Fisher Scientific, Waltham, MA) and subsequent analysis using a Cellomics ArrayScan VTI high content imaging platform was used to evaluate cortical cell neurite outgrowth and branching as described in Radio et al. (2008) for differentiated PC-12 cells [58]. The Cellomics ArrayScan VTI Neuronal Profiling Bioapplica- 
Table 6: Pharmacokinetic estimates of pyrethroid brain concentrations.

\begin{tabular}{lccc}
\hline & Administered Dose $(\mathrm{mg} / \mathrm{kg})$ & Time $(\mathrm{h})$ & Brain Concentration $(\mu \mathrm{M})$ \\
\hline Deltamethrin $^{\mathbf{a}}$ & 0.3 & 6 & 0.005 \\
& 1 & 6 & 0.0169 \\
& 3 & 6 & 0.050 \\
Permethrinb $^{b}$ & 1 & 6 & 0.060 \\
& 10 & 6 & 0.582 \\
& 100 & 6 & 5.940 \\
\hline
\end{tabular}

a Estimates based on Mirfazaelian et al. (2006).

b Estimates based on Tornero-Velez et al. (2007).

tion used a 10X objective and sampled a sufficient number of fields for the analysis of at least 200 cells per well. Data represent the mean \pm standard error across 3 replicate experiments. Cellular viability was determined in cortical cell cultures grown as described above in opaque 96-well plates using the CellTiter-Glo Viability Assay (Promega Corp., Madison, WI) as described in Radio et al. (2008) [58]. Luminescence was measured thirty minutes after adding the reagent using a FLUOstar Optima plate reader (BMG LABTECH, Durham, NC).

\section{Results}

Microarray dose-response analyses

Both the PIR (isotonic) and SAM (linear) penalized regression methods identified dose-dependent increases and decreases in mRNA expression in the frontal cortex 6 $\mathrm{h}$ after an acute, oral exposure to both deltamethrin and permethrin. A comparison of the PIR and SAM regression models demonstrate that the two methods yield similar results in terms of identifying dose-responsive probe sets for both deltamethrin and permethrin (Figure 1A \&1B). SAM analyses identified a small number of probe sets with dose-dependent increases in expression following either deltamethrin $(n=7)$ or permethrin $(n=10)$ exposure using the permutation-based FDR values as the significance criteria $(q<0.10$, see Figure 1A \&1B). The PIR analyses did not identify any probe sets for either pyrethroid with dose-dependent changes in expression at $q<0.10$. A less statistically conservative method of identifying doserelated changes in probe set expression identified a larger number of significantly altered probe sets than that observed using the FDR criteria. Using a screening threshold of $p<0.01$ the SAM analysis identified 70 and 61 probe sets with dose-dependent changes in expression for deltamethrin and permethrin, respectively, while the PIR analysis identified 93 and 85, respectively (Figure 1A-B). The overlap between probe sets identified as dose-responsive using the empirical $p$-value thresholds is considerable but incomplete. Overall, these parallel methods yield comparable results in that a rank-ordered list of dosedependent changes in expression constructed using either the PIR or SAM test-statistics identifies the same groups of probe sets as being the most significantly changed within both the deltamethrin and permethrin test cohorts

To minimize the inclusion of false positives in qRT-PCR prioritization lists, all the probe sets for each compound that had empirical $p$-values $<0.01$ in either the SAM or PIR regression methods were additionally analyzed with a one-way ANOVA with dose as the independent factor, followed by a Benjamini-Hochberg multiple testing correction (significance threshold, $p<0.05$ ). For deltamethrin and permethrin, 95 of $109(87.1 \%)$ and 53 of 89 (59.5\%) probe sets passed the ANOVA significance threshold. The full list of probe sets considered significantly dose-responsive for deltamethrin $(n=95)$ and permethrin $(n=53)$ are listed in Additional files 3 and 4. Probe sets included in Additional files 3 and 4 that correspond to known protein-coding RefSeq database entries were considered candidates for qRT-PCR confirmation in dose-response Cohorts 3 and 4 and are listed in Tables 2 and 3.

The dose-dependent changes in mRNA expression identified with the above analyses are relatively small in magnitude, < 2-fold change from control, and have varying patterns of expression across dose (Figure 2). Post-hoc analysis (Dunnett's mean contrast test) of these doseresponse functions indicate that significant alterations in mRNA expression occur at doses below those needed to produce acute behavioral effects (Figure 2, insets). A majority of the probe sets identified as dose-responsive had mean expression values in the $3 \mathrm{mg} / \mathrm{kg}$ deltamethrin and $100 \mathrm{mg} / \mathrm{kg}$ permethrin dose groups different from those in the vehicle treated control group $(78.9 \%$ and $77.3 \%$, respectively). Of those probe sets, $25.3 \%$ and $19.5 \%$ also had mean expression values in the $1 \mathrm{mg} / \mathrm{kg}$ deltamethrin and $10 \mathrm{mg} / \mathrm{kg}$ permethrin dose groups different from controls. These latter doses are below those needed to produce acute neurotoxic effects on behavior. In addition, these data demonstrate that the PIR analyses detected a greater number of probe sets with mean expression values in the behavioral "NOAEL" dose groups (see Table 1) as being different from control as compared to the SAM analyses (compare Figure 2B \&2E, insets to Fig- 

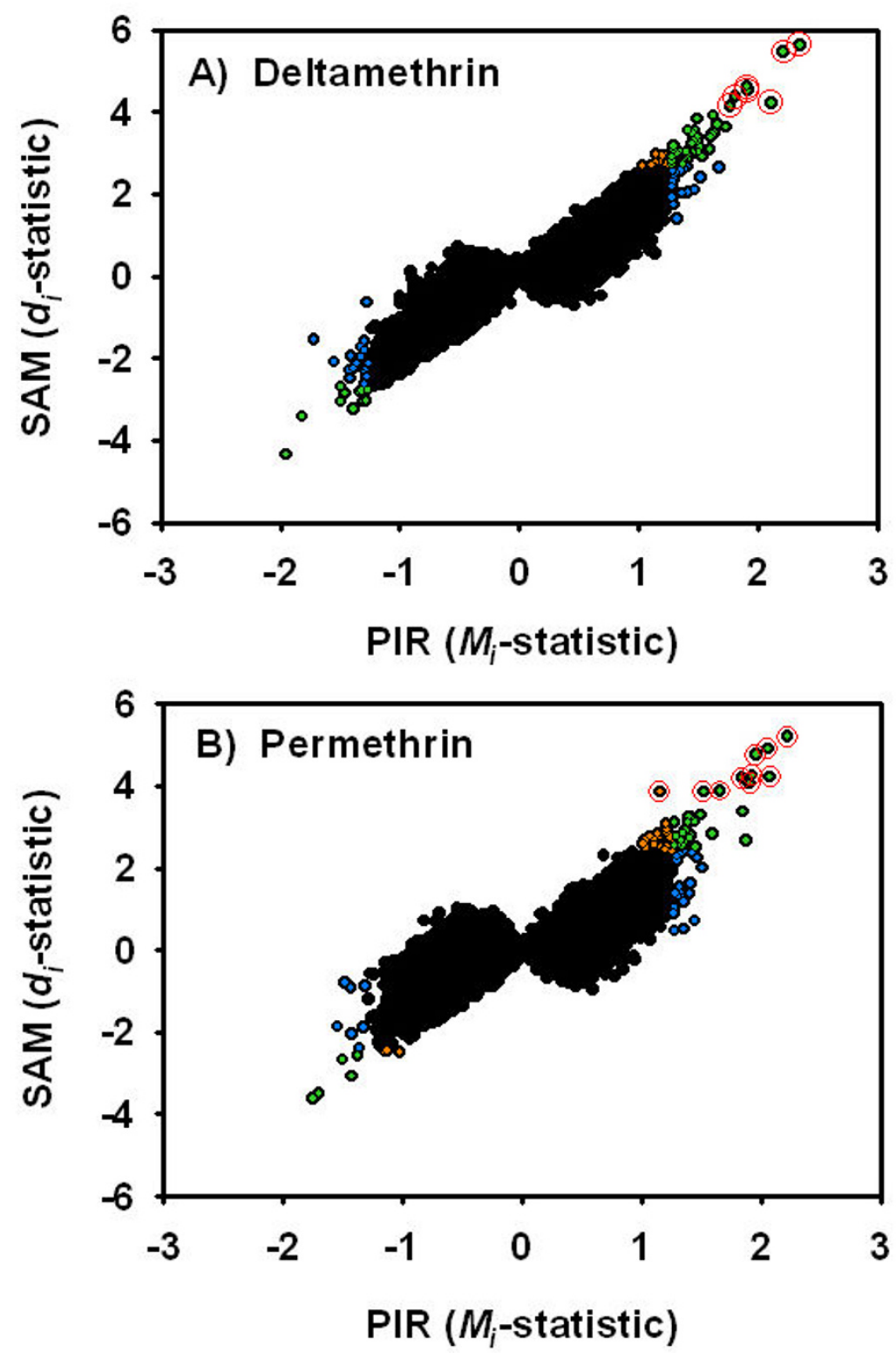

Figure I

Comparison of PIR and SAM regression methods. Panels A \& B plot the penalized isotonic regression (PIR) test statistic $\left(M_{i}, x\right.$-axis) against the penalized linear regression (SAM) test statistic $\left(d_{i}, y\right.$-axis) for deltamethrin and permethrin, respectively. All 3I,042 probe sets present on the Affymetrix Rat 2302.0 GeneChip ${ }^{\circledR}$ are shown. Data points in green have an empirical $p$ value $<0.0$ I for both the PIR and SAM methods. Data points in blue have an empirical $p$-value $<0.0$ I for the PIR regression only. Data points in orange have an empirical $p$-value $<0.01$ for the SAM regression only. In the deltamethrin and permethrin analyses, $49.5 \%$ and $53.7 \%$ of all probe sets identified by either the PIR or SAM method had $p<0.0$ I for both methods. Data points circled in red have a $q$-value $<0.10$ in permutation-based FDR calculations employed in the SAM algorithm. Note that the rank order of statistical significance was similar between the two methods in that probe sets commonly identified using the PIR or SAM method tend to appear in the upper-right and lower left hand corners of the scatterplots (green points). 
PIR \& SAM
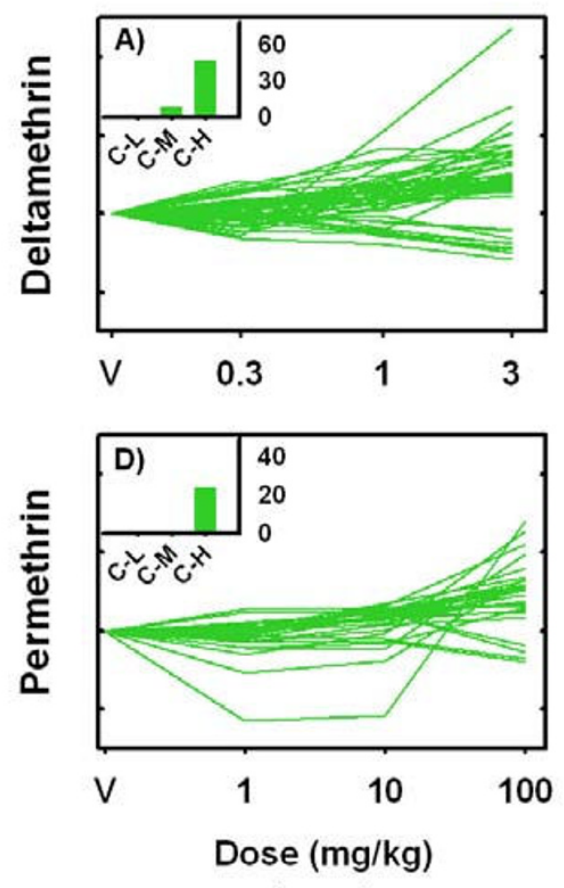

log scale
PIR Only
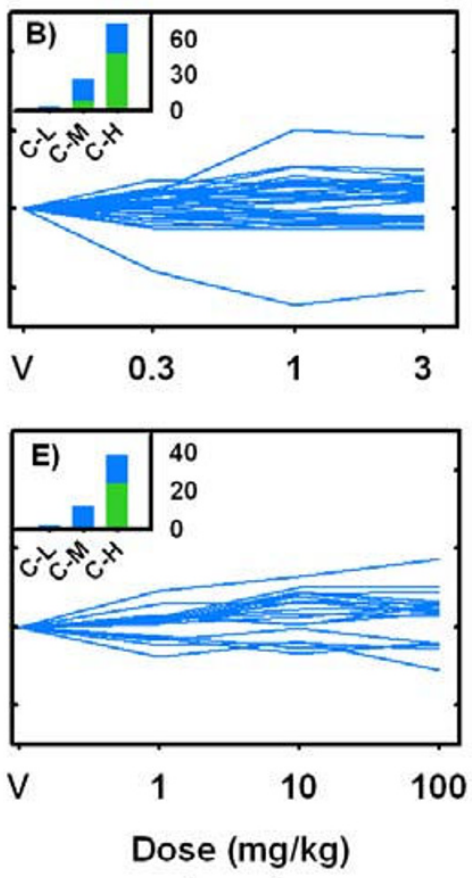

$\log$ scale
SAM Only
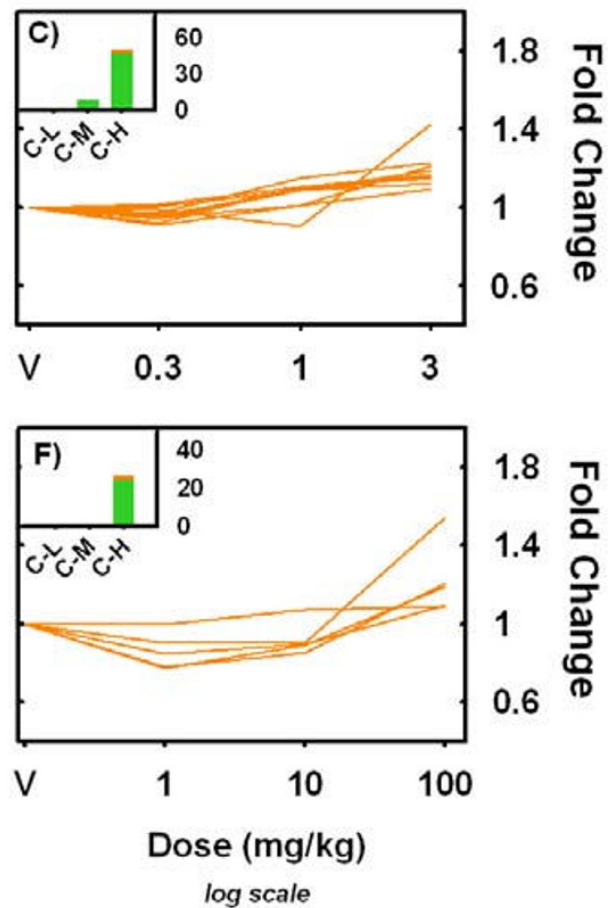

1.8

1.4

$\frac{T}{2}$
$\frac{0}{2}$
$\frac{2}{\sigma}$
$\frac{0}{0}$

Figure 2

Dose-response functions identified by PIR and SAM regression methods. Panels A-F plot dose-response functions for probe sets identified by PIR (B \& E), SAM (C \& F) or both regression methods (A \& D) for deltamethrin (A-C) and permethrin (D-F). Only probe sets that had a Benjamini-Hochberg adjusted $p$-value $<0.05$ for a main effect of dose in a one-way ANOVA are shown. For each probe set expression summaries for each treatment group were normalized to vehicle control and plotted as fold-change from control. The color scheme corresponds to that used in Figure I, with green curves being detected by both PIR and SAM regression methods (A, D), blue curves being detected exclusively with the PIR method (B, E) and orange curves being detected exclusively with the SAM method (C, F). Insets on each panel are the summated results of a Dunnett's many-to-one mean contrast test performed within each probe set comparing the means of the lowest (C-L), middle (C-M) and highest (C-H) doses to the mean of vehicle treated control. $y$-axis is number of probe sets identified under each comparison at a significance level of $p<0.05$. Note the green portion of the stacked bars in the insets are the same values in inset panels A-C and D-E, respectively.

ure $2 \mathrm{C} \& 2 \mathrm{~F}$, insets).

\section{Comparison of transcriptional effects across compounds}

A comparison of the probe sets identified as dose-responsive in the PIR and SAM regression analyses demonstrates that the transcriptional response elicited by the two pyrethroids has some common characteristics. The panels in Figures 3 plot the $\log _{10}$ of the empirical $p$-values associated with the PIR regression (3A) or SAM regression (3B) for each probe set identified as dose-responsive for either deltamethrin or permethrin. Data from the PIR regression analyses demonstrate that expression of $27.2 \%$ of all probe sets identified as dose-responsive for either pyrethroid are significantly altered by both compounds at an empirical $p$-value threshold of $p<0.05$ (Figure 3A). Likewise, SAM analyses demonstrated that $27.8 \%$ of all dose- responsive transcripts are altered by both pyrethroids (Figure $3 \mathrm{~B}$ ). Differences in the global transcriptional response profiles between pyrethroids are also apparent.

\section{Quantitative real-time RT-PCR}

Table 4 summarizes the results of the qRT-PCR assays and compares them to the fold-change expression values derived from the microarray study. Of the nine transcripts examined by qRT-PCR in Cohort $3, \mathrm{Ca}^{+2} /$ calmodulin dependent protein kinase $1 \gamma(\mathrm{Camk1g})$ and dopa decarboxylase $(D d c)$ were commonly affected by both compounds indicating that for these genes there was no differences in the changes in expression elicited by equipotent doses of either pyrethroid. Camk1g qRT-PCR expression values closely resembled those observed in the microarray study. In contrast to Camk1g, the microarray 
PIR Regression

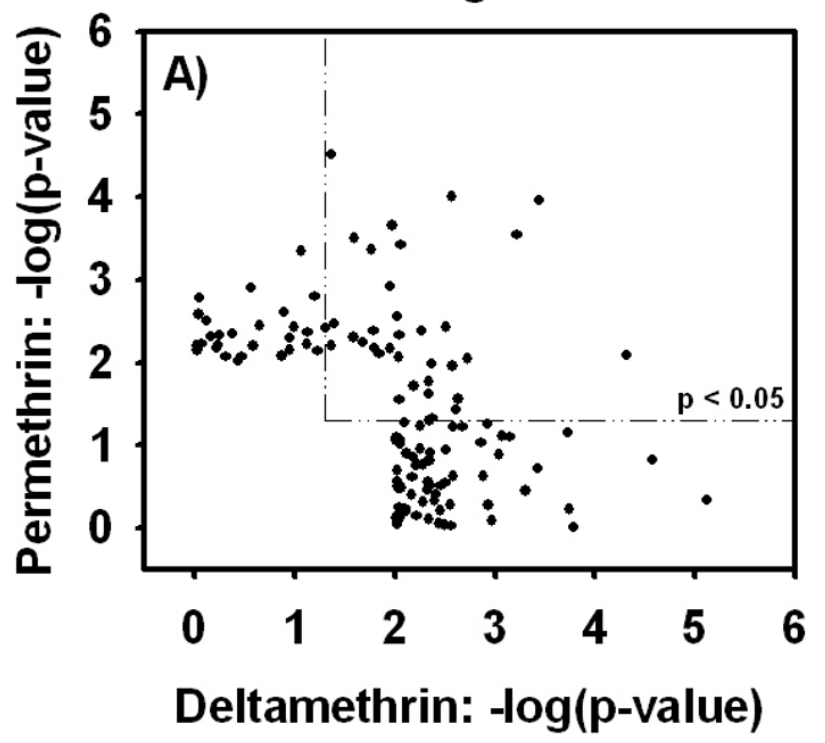

SAM Regression

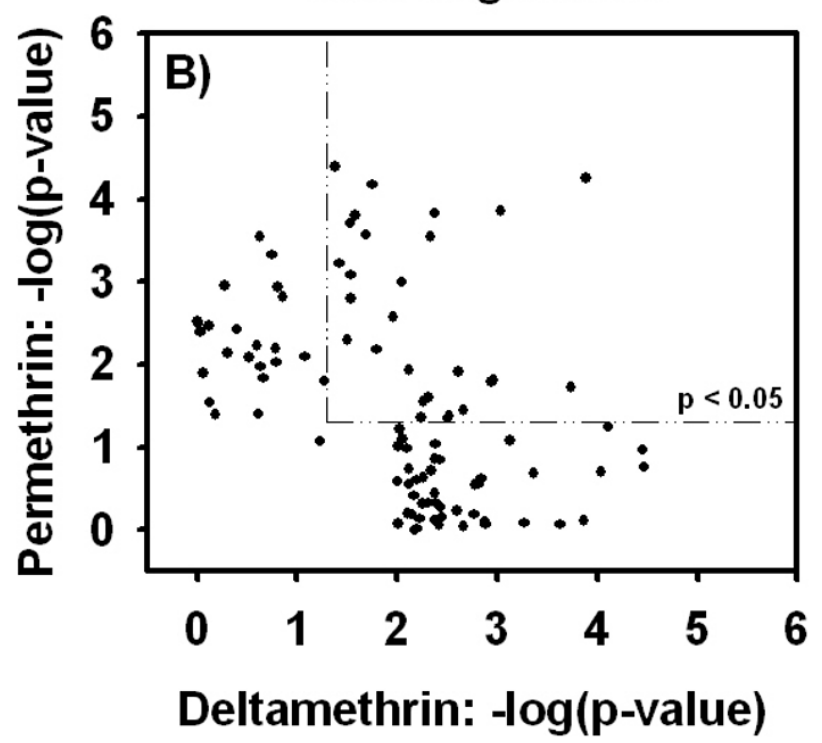

Figure 3

Comparison of probe sets identified by PIR or SAM between pyrethroids. Panels $A$ and $B$ plot the -log 10 (empirical $p$ value) for deltamethrin ( $x$-axis) against the - $\log _{10}$ (empirical $p$-value) for permethrin $(y$-axis) for probe sets identified during PIR or SAM regression analyses, respectively. All probe sets that had a Benjamini-Hochberg adjusted $p$-value $<0.05$ in a one-way ANOVA for either permethrin or deltamethrin are included in the plot. Dashed boxes represent empirical $p$-value thresholds of $p<0.05$. All points in the upper right of the figures, within the dashed boxes, meet the respective $p$-value criteria for both pyrethroids. $27.2 \%$ and $27.8 \%$ of all probe sets identified during PIR or SAM analysis, respectively, had empirical $p$-values of $p<$ 0.05 for both compounds.

dose-response cohort demonstrated a dose-related change in $D d c$ expression for deltamethrin only, even though a clear dose-dependent decrease in Ddc mRNA expression was observed in both the deltamethrin and permethrin qRT-PCR cohorts.

A significant interaction between compound and EDL was observed for glycerol-3-phosphate dehydrogenase 1 (Gpd1) and FK506-binding protein 5 (Fkbp51), indicating that equipotent doses of the two pyrethroids did not elicit similar changes in expression at $6 \mathrm{~h}$ post-exposure. A main effect of dose was observed for Gpd1 and Fkbp51 mRNA only for deltamethrin (Table 4). The qRT-PCR expression values for Gpd1 and Fkbp51 closely match those observed in the microarray study.

The immediate early genes (IEG), FBJ murine osteosarcoma viral oncogene homolog (c-fos) and early growth response 1 (Egr1) were differentially affected by the two pyrethroids at $6 \mathrm{~h}$ post-exposure, however, no significant main effect of dose (EDL) was observed for either compound. For deltamethrin, the direction of fold-change for $c$-fos and Egr1 is down in most dose groups measured by qRT-PCR. In contrast, for permethrin no change in the expression of $c$-fos and Egr1 mRNA was observed across dose groups in the qRT-PCR cohort. While $c$-fos and Egr1 expression at $3 \mathrm{mg} / \mathrm{kg}$ deltamethrin and $100 \mathrm{mg} / \mathrm{kg}$ permethrin reflect the direction of fold-change observed in the microarray study, very little similarity is apparent between qRT-PCR and microarray expression values for these genes at the lower dose levels (Table 4).

There were no effects of pyrethroid exposure on mRNA expression for heat shock $27 \mathrm{kDa}$ protein (Hsp27), brain derived neurotrophic factor (BDNF) or Ras association (RalGAS/AF-6) domain family 6 (Rassf5) (data not shown). In the case of BDNF, qRT-PCR expression values closely approximate the expression values observed in a second probe set not identified as dose-responsive in the microarray analyses (data not shown).

Characterization of the time course of mRNA expression for Camk1g, Gpd1, c-fos and Egr1 demonstrates that altered expression of these transcripts also occurs at times earlier than $6 \mathrm{~h}$ following acute, oral pyrethroid exposure (Figure 4, Additional file 5). Treatment-related increases in Camk1g and Gpd1 mRNA expression were observed for both deltamethrin and permethrin. For deltamethrin, 
both Camk1g and Gpd1 mRNA had maximally induced expression at $3 \mathrm{~h}$ followed by persistent elevations at $6 \mathrm{~h}$ (Figure 4). For permethrin, both Camk1g and Gpd1 had maximal induction at $6 \mathrm{~h}$ preceded by slight elevations at $3 \mathrm{~h}$. Permethrin-mediated Gpd1 induction was statistically significant while Camk1g induction reflected the trends observed in the dose-response cohorts but did not reach statistical significance. Ddc mRNA expression was decreased following both deltamethrin and permethrin exposure. For deltamethrin decreased expression began at $6 \mathrm{~h}$ and persisted through $9 \mathrm{~h}$ while for permethrin, expression decreased at $6 \mathrm{~h}$ only. The changes in $D d c$ mRNA expression over time were consistent with those observed in the qRT-PCR cohort

Both deltamethrin and permethrin increase the expression of the IEGs $c$-fos and Egr1, albeit with different temporal characteristics. Expression of $c$-fos and Egr 1 increases at $3 \mathrm{~h}$ for deltamethrin and returns to control levels at $6 \mathrm{~h}$. For permethrin, expression of $c$-fos and Egr 1 increases at 3 $h$, remains persistently elevated at $6 \mathrm{~h}$ and returns to control levels by $9 \mathrm{~h}$. The large increases in c-fos and Egr1 for permethrin and not deltamethrin are consistent with the microarray data as these two genes were identified as dose-responsive at $6 \mathrm{~h}$ for the former and not the latter compound. However, the data in Figure 4 demonstrate that the two pyrethroids, in fact, elicit qualitatively similar responses in the expression of $c$-fos and Egr1. The expression of another IEG, BDNF, is apparently not affected by pyrethroids under the dosing paradigm used in this study.

\section{Significant Analysis of Function and Expression (SAFE)}

Seven GO categories were identified as commonly enriched for both pyrethroids using SAFE analysis and Fisher's $\chi^{2}$ method (Table 5). The composition of the commonly enriched categories for both chemicals included genes involved in neuronal morphogenesis, intracellular $\mathrm{Ca}^{+2}$ signaling and small molecule transport. In addition, five GO-BP categories and two canonical KEGG pathways were identified as enriched in the individual SAFE analyses of permethrin and deltamethrin, respectively (Table 5). For permethrin, the SAFE findings include enriched gene categories related to neuronal morphogenesis and developmental patterning. For deltamethrin the SAFE findings include two KEGG metabolic pathways, one of which involves synthesis of the precursor molecules for monoamine neurotransmitters.

SAFE plots of the GO categories 'morphogenesis of a branching structure' and ' $\mathrm{Ca}^{+2} /$ calmodulin dependent protein kinase complex' demonstrate the significant category enrichment for both permethrin and deltamethrin (Figure 5). This is evidenced by the divergence of the stair step line from the unity line near the far left of Figure 5, panels A-D. A SAFE plot of a GO category not significantly enriched for either compound is given in Figure 5, panels $\mathrm{E}-\mathrm{F}$ for comparison purposes. The most significant doseresponsive transcripts for each of the enriched GO categories are illustrated in the heatmaps to the right of Figure 5, panels A-D. These heatmaps demonstrate that appreciable dose-dependent increases in the expression of probe sets contained within the enriched GO categories occurs following pyrethroid exposure.

\section{Pyrethroid effects on neurite length and branching in primary mixed cortical cell cultures}

Both deltamethrin and permethrin produce an increase in the number of neurite branch points following a $96 \mathrm{~h}$ exposure (Figure 6A \&6D). The range of predicted tissue concentrations (in $\mu \mathrm{M}$ ) from the pharmacokinetic predictions listed in Table 6 are marked near the $x$-axes and correspond well to areas along the in vitro dose-response curve where changes in branching were observed. An average increase of $\sim 25 \%$ above control in the number of neurite branch points was observed at nominal media concentrations ranging from $0.01-0.03 \mu \mathrm{M}$ deltamethrin and $0.01-3 \mu \mathrm{M}$ permethrin. No significant increase in total neurite length was observed for either compound save at the $0.01 \mu \mathrm{M}$ exposure level for permethrin (Figure $6 \mathrm{~B} \& 6 \mathrm{E}$ ). Changes in cell viability were not apparent in the concentration ranges tested (Figure 6C \&6F).

\section{Discussion}

A principle finding of the present study was that dosedependent alterations in gene transcription occur in the cortex at doses of deltamethrin and permethrin below those required to elicit acute neurotoxic effects in the whole animal. Both similarities and differences in the overall transcriptional response were observed when comparing the two pyrethroids. Quantitative real-time RTPCR analysis in additional cohorts of animals provided independent biological and technical replicates of the findings from the microarray data set. In addition, transcripts for which the time course of gene expression was characterized demonstrated qualitative similarities in the response for both pyrethroids. SAFE analysis of the microarray data identified several GO categories jointly enriched by both deltamethrin and permethrin including some related to branching morphogenesis. Subsequently, a significant increase in the number of neurite branch points was observed in a primary cortical cell culture model.

\section{Microarray dose-response analyses}

Dose-dependent alterations in transcript expression were observed in frontal cortex $6 \mathrm{~h}$ following acute exposure to pyrethroids. Prior to experimentation, the shape of the dose-response curve for any potential alterations in gene transcription was unknown. Visual inspection of the data demonstrated a definite heterogeneity in the types of 

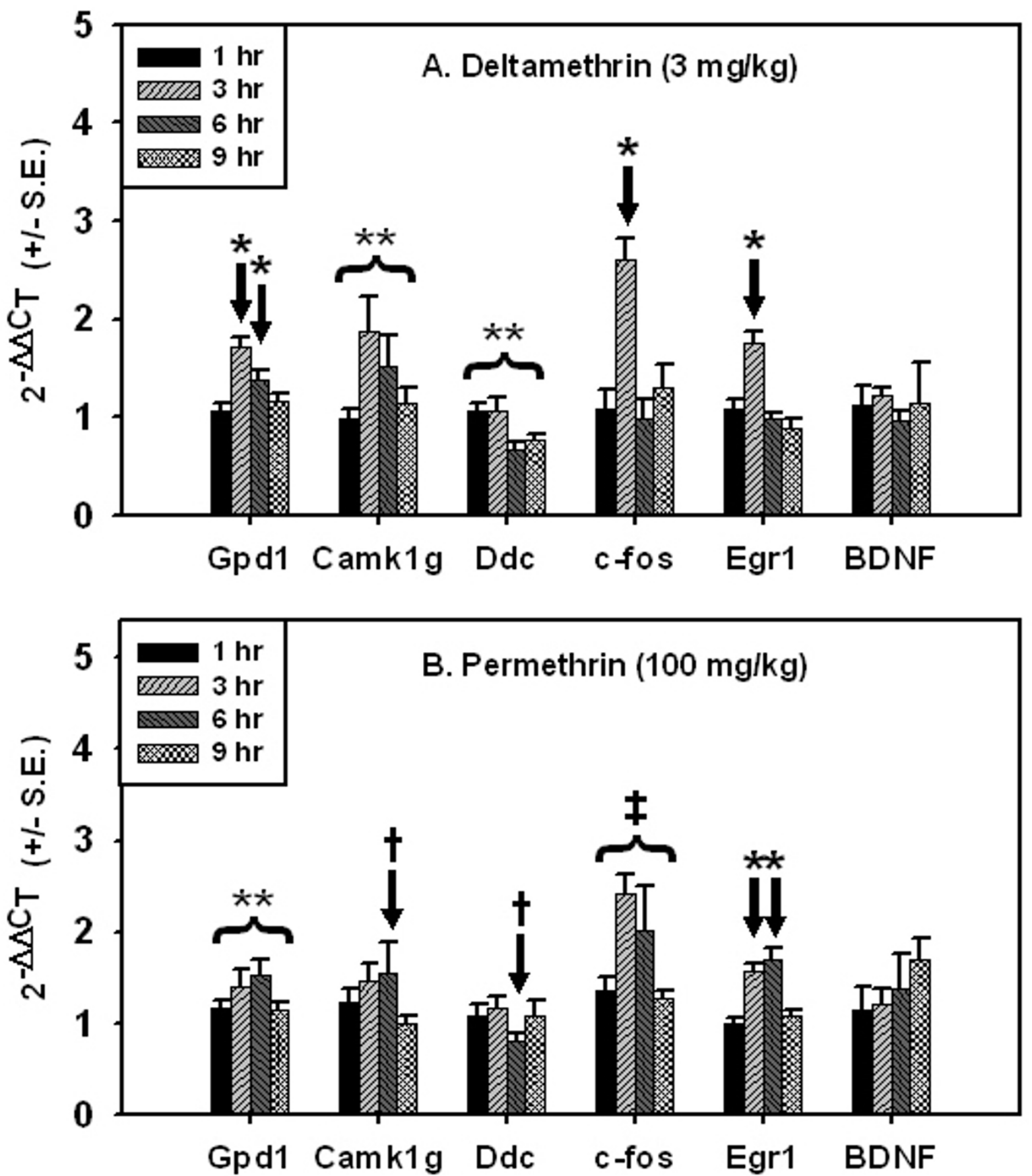

Figure 4

qRT-PCR time course results. Transcript expression over time following a single acute dose of $3 \mathrm{mg} / \mathrm{kg}$ deltamethrin (top) or $100 \mathrm{mg} / \mathrm{kg}$ permethrin (bottom). Gene symbols are listed on the $y$-axis. Data were analyzed using two-way ANOVA followed by one-way ANOVA within time points were interaction was observed. (**) denotes no interaction of time and treatment and a main effect of treatment $(p<0.05)$. ( $\ddagger)$ denotes no interaction of time and treatment and a main effect of both time and treatment $(p<0.05)$. $\left({ }^{*}\right)$ denotes a significant effect of treatment for that time point $(p<0.05)$. $(\dagger)$ denotes a significant main effect of dose from qRT-PCR dose-response analysis (Table 4). Values for time-matched vehicle controls are not shown. A summary of the statistical analyses performed on these data is provided in Additional file 5. 

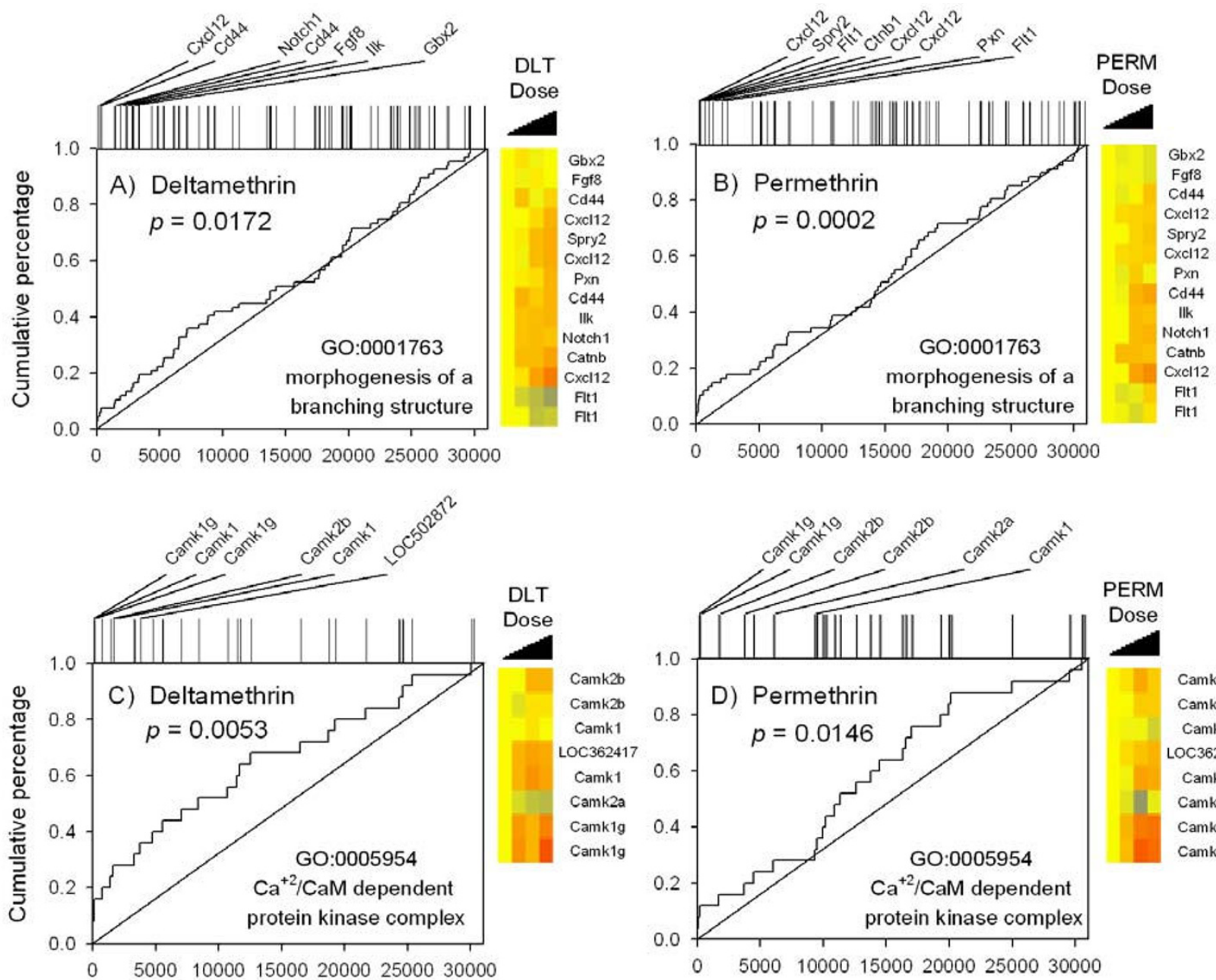

PERM

Camk2b

Camk2b

Camk1

LOC362417

Camk1

Camk2a

Camk1g

Camk1g

l 50001000015000200002500030000

DLT

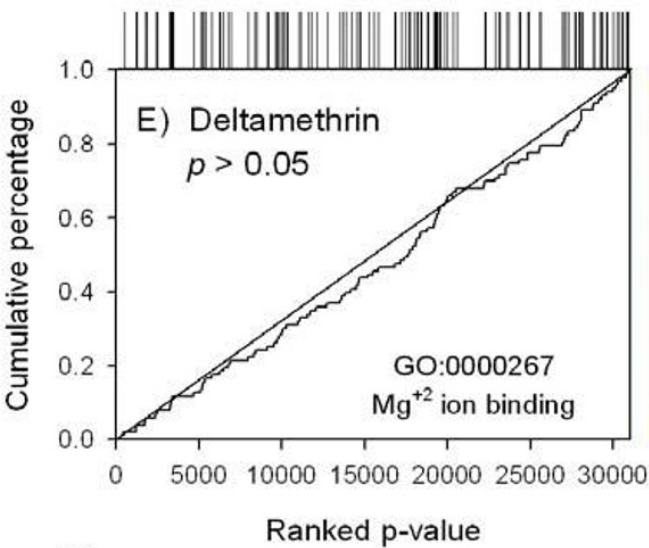

Dose

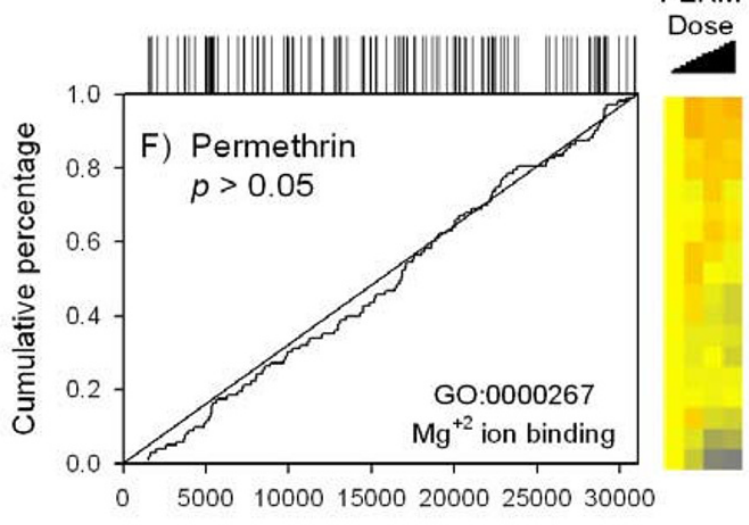

G)

Ranked p-value

Ranked p-value 
Figure 5 (see previous page) Composition and expression patterns of significantly enriched GO categories from SAFE analysis. Panels A-D are SAFE plots for two commonly enriched categories for both deltamethrin (A \& $C$ ) and permethrin (B \& D). Panels $E$ \& F are SAFE plots for a category not enriched for either deltamethrin $(E)$ or permethrin $(F)$. The $x$-axis of each plot denotes the position of all probe sets in a rank ordered list of significance (from left to right) according to the empirical $p$-value from a linear regression across dose. The $y$-axis is a cumulative percentage calculated by taking the rank position of a given probe set either within the entire data set (solid unity line) or the interrogated Gene Ontology sub-category (solid stair-step line) and dividing them by the total number of probe sets contained within the entire data set or interrogated category, respectively. The degree of deviation of the stair-step line from the unity line indicates enrichment. The probe sets (excluding ESTs) that are ranked highest in significance for each GO category for both compounds in panels A-B and C-D are denoted at the top of each panel and included in a heatmap to the side of the respective panels. In the heatmaps, each row of tiles is a probe set and each column of tiles represents the mean fold-change from control with increasing doses of each compound running from right to left. Colorbar for heatmaps is given in panel $\mathrm{G}$.

dose-response functions produced by these pyrethroid exposures (see Figure 2). The biological factors mediating this heterogeneity are unclear but may involve activation of different intracellular signaling pathways at different points along the dose range [59-62]. To generate lists of candidate genes for qRT-PCR follow-up that captures this heterogeneity, the GeneChip ${ }^{\circledR}$ expression data was analyzed using two independent but similarly structured regression methods: SAM and a novel PIR. Both methods identified qualitatively similar dose-related alterations in gene expression within each compound (Figure 1A \&1B). The SAM regression model detected a number of doseresponsive transcripts with expression levels different from control only at the highest pyrethroid dose (Figure 2). However, PIR identified other dose-related changes with small, but significant, increases or decreases in expression that were similar in magnitude at both the "NOAEL" and "high" pyrethroid doses (Figure 2B \&2E) and not detected by SAM. These dose-responsive transcripts may in fact be biologically relevant responses to acute pyrethroid intoxication which would have been excluded using the standard SAM analysis. Therefore, while both SAM and PIR identified the same sub-set of transcripts within compound, the PIR method detected a larger component of the global transcriptional response of the cortex composed of expression changes that do not fit a linear model.

The regression analysis frameworks detailed in this work were used exclusively as an identification and prioritization method for selection of genes for subsequent qRTPCR analyses. Conclusions concerning the biological significance of individual transcriptional changes were reserved for those transcripts successfully replicated by qRT-PCR in independent cohorts of test subjects. For the goals of this study, the risk of excluding true positives in the microarray data analysis outweighed the caveat of including false positives from the final list of prioritized targets. Thus, the modified protocol of regression screening and subsequent ANOVA based analyses was adopted.

\section{Comparison across compounds}

The present data demonstrate both similarities and differences in the global transcriptional response in rat cortex to acute, low-dose deltamethrin and permethrin exposure. Similarities in the global transcriptional response across compounds suggest that these two pyrethroids may affect common biological pathways (Figure 3). The differences observed between compounds in the global transcriptional response (i.e. microarray dataset) are likely due to a combination of two factors: 1) authentic heterogeneity in the pharmacodynamic activities of deltamethrin and permethrin on gene transcription and 2) a slight offset in the time course of qualitatively similar responses across compounds. In addition, time course data implies that additional alterations in gene expression not detected in the 6 $\mathrm{h}$ dose-response study may occur at time points other than the one sampled. The qRT-PCR data shown here support this conclusion (Figure 4).

The results of the SAFE functional category level analysis support the conclusion that the biological activities of the two pyrethroids overlap. Several categories were found to be commonly upregulated between the two compounds. Similarities are not surprising, given that both pyrethroids act on mammalian VSSCs [12,32]. Whether the individual gene changes or impacted functional categories are directly linked to this site of action, remains yet to be determined. Importantly, these data provide guidance on some novel cellular functions affected by pyrethroids.

\section{Biological significance of experimental findings}

Interestingly, probe sets corresponding to the primary molecular targets for pyrethroids were not altered for either pyrethroid tested in the microarray study. Specifically, there were no treatment related changes in any of the VSSC or VSCC isoforms/subunits or any subunits that comprise neurotransmitter receptors complexes [63-66]. This finding is supported by in vitro data [27] that characterized the global transcriptional response of cortical neurons exposed to a variety of pharmacological agents that 
Deltamethrin Permethrin

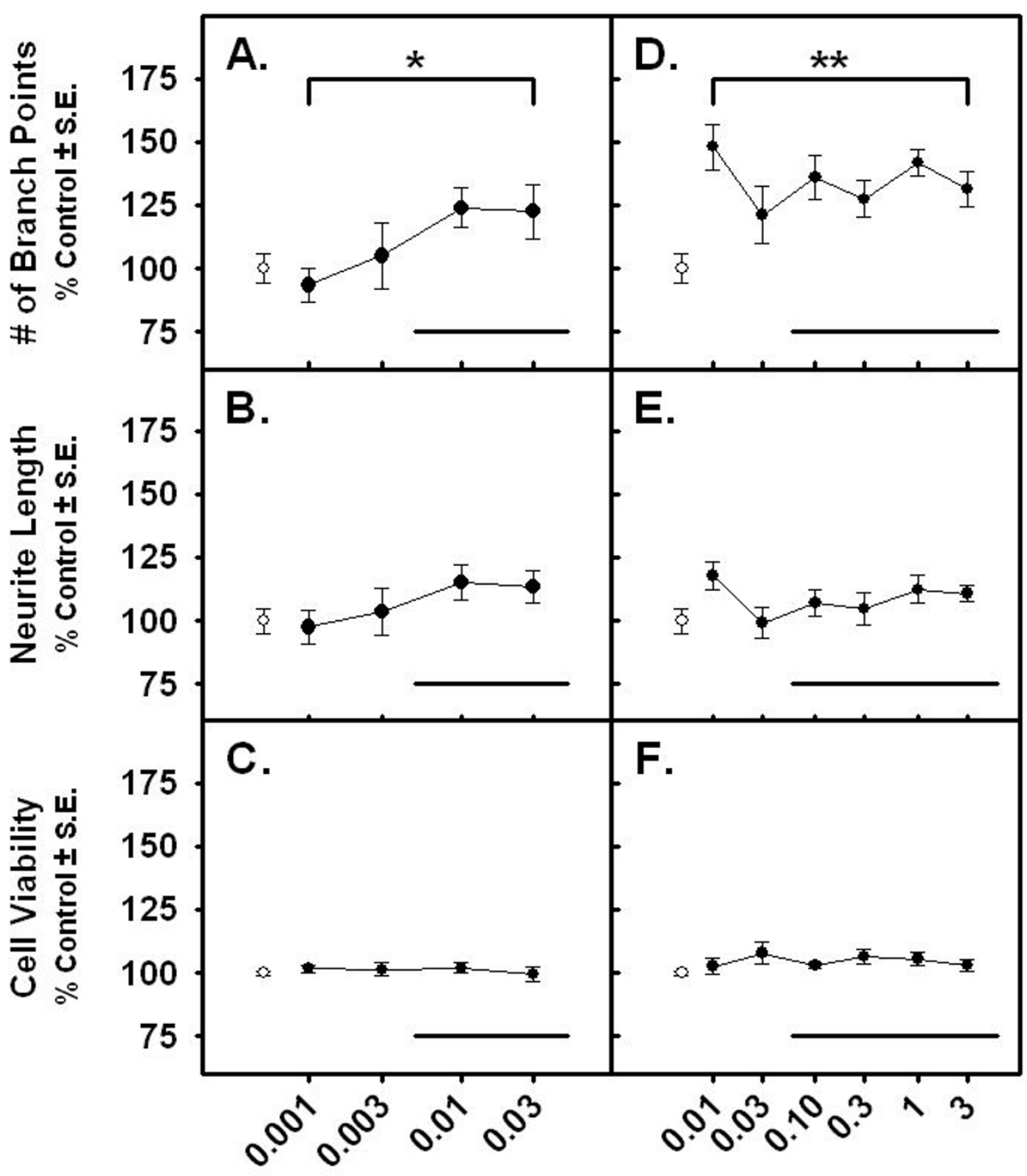

\section{Concentration $(\mu \mathrm{M}) \quad$ Concentration $(\mu \mathrm{M})$}

\section{Figure 6}

Pyrethroid effects on branching and neurite length in primary cortical cell cultures. Changes in the total number neurite of branch points $(A \& D)$, total neurite length ( $B$ \& $E)$ and cell viability $(C \& F)$ in primary cortical cell cultures exposed to deltamethrin $(A-C)$ or permethrin $(D-F) . n=3$ replicate experiments. Values for each end point are normalized to untreated controls ( \pm standard error). Untreated control values are shown in white. The bold lines underneath each curve represent the range of estimated brain concentrations expected to occur during the in vivo exposures used in the present study (Mirfazaelian et al. 2006 and Tornero-Velez et al. 2007). Significance was determined using a One-way ANOVA, $*=p<0.10$, $* *=p<0.05$. 
altered firing rates. No changes in the expression of VSSC or VSCC isoforms/sub-units or neurotransmitter receptors were identified in this study in response to increases in neuronal firing rates [27]. Since a primary action of pyrethroids is to change firing rates [67], the present data do not support transcriptional induction or repression of VSSCs, VSCCs or neurotransmitter receptor subunits as a neuronal response to acute pyrethroid exposure. These data do not exclude transcription-independent changes in the expression or functional state of these channels known to occur following excitatory stimuli [68-71].

The immediate early transcription factors $c$-fos and Egr1 were upregulated by deltamethrin and permethrin. This is consistent with IEG expression changes in the cortex following acute pyrethroid exposure [29,72]. Increased Egr1 and $c$-fos expression supports that deltamethrin and permethrin increased neuronal excitation in the present study. Egr 1 and $c$-fos are among the genes induced by increased neuronal firing in cortical cells in culture [27], as well as in vivo following stimuli that produce neuronal excitation $[73,74]$. Induction of IEG mRNAs is a rapid transcriptional response of neurons following increased activity [75-78]. The time course for the expression of the IEGs $c$-fos and Egr1 does not support de novo gene transcription as being responsible for mediating the acute behavioral effects of pyrethroids. The earliest time that increased IEG expression is observed in the present study is at $3 \mathrm{~h}$ : IEG expression is at control levels at $1 \mathrm{~h}$. Onset of behavioral effects following oral pyrethroid exposure occurs prior to the onset of increased IEG expression (i.e. $30 \mathrm{~min}-1 \mathrm{~h}$ ) [79]. Therefore, the IEG induction described here can not mediate the acute neurotoxic signs of pyrethroid intoxication, but instead are markers of neuronal excitation.

The present study found dose- and time-dependent increases in the expression of Camk1g mRNA. Data from in vitro models of developmental morphogenesis in neurons indicates that increased expression of Camk1g (Table 4 and Figure 4) may alter the structure and function of pyrethroid-sensitive neurons. Wayman et al. (2006) [80] demonstrated that Camk1g plays a specific role in the activity-dependent growth of hippocampal neurons between 7-9DIV by activating a Ras/MEK/ERK/CREB/ Wnt2 signaling cascade in response to excitatory stimuli. In addition, Takemoto-Kimura et al. (2007) [81] demonstrated that Camk1g participates in a Rac signaling pathway that mediates the morphogenesis of cortical neurons. In both those studies, artificial knockdown or over-expression of Camk1g altered outgrowth of neuronal processes in a development context $[80,81]$. The role of Camk1g in maintenance and plasticity of neuronal processes in the adult CNS is currently unknown. Furthermore, there is evidence in the literature that Camk1g mRNA expression is regulated by changes in neuronal firing patterns similar to IEGs. Changes in neuronal firing rates correlates with increases or decreases in the expression of Camk1g mRNA $[27,82-85]$. These observations support that pyrethroidmediated changes in neuronal firing rates could mediate changes in the expression of Camk1g, which may in turn lead to changes in neuronal morphology (see below), especially during development.

The transcriptional upregulation of glycerol-3-phosphate dehydrogenase 1 (Gpd1) and FK506-binding protein (Fkbp51) mRNA (Table 4, Figure 4) indicate: 1) that pyrethroid exposure activates the hypothalamic-pituitaryadrenal (HPA) axis and 2) that non-neuronal cell populations in the CNS are sensitive to pyrethroids. The proteins encoded by Gpd1 and Fkbp51 are expressed in the brain exclusively in oligodendrocytes [86] and T-cell lymphocytes [87]. Both the Gpd1 and Fkbp51 genes contain glucocorticoid receptor binding motifs either in the upstream promoter region (Gpd1) [88] or in an intronic region (Fkbp51) [89] and increased expression of both is dependent upon glucocorticoid hormone stimulation [90,91]. Glucocorticoids are released in the circulation from the adrenals in response to a variety of stressors and increased circulating corticosterone levels were reported in the rat following deltamethrin exposures; albeit at very high, intravenous doses [92]. It is likely that increases in Gpd1 and Fkbp51 expression may be components of a generalized, non-specific stress response brought about by overstimulation of the HPA axis by pyrethroids. The potential impact of increased Gpd1 and Fkbp51 expression on the health and function of affected glia, to date, is unclear.

Decreases in the expression of aromatic L-amino acid decarboxylase $(D d c)$ suggest that pathways controlling monoaminergic neurotransmitter synthesis may be affected by pyrethroids. $D d c$ is the final enzyme in the synthesis pathways of dopamine and serotonin [93]. Previous reports note a depletion of dopamine and serotonin in a variety of brain regions following repeated exposure to deltamethrin [94-96]. In the case of dopamine depletion, two of these studies demonstrate concurrent decreases in the expression of tyrosine hydroxylase, the penultimate enzyme in dopamine synthesis $[95,96]$. The mechanism controlling Ddc mRNA repression following pyrethroid exposure is unclear, but provides support that monoaminergic neurotransmitter systems are sensitive to the compounds.

The changes in gene transcription observed in the present study occur at doses at or near the threshold for eliciting acute neurobehavioral signs of intoxication in the whole animal $[33,97,98]$. Time course data (Figure 4) demonstrate that transcriptional changes are transient and con- 
sistent with the onset and recovery of actue behavioral effects following acute, oral exposures observed in previous studies $[97,99]$. Currently, it is unclear if these transient gene expression changes are simply an adaptive response of the nervous system to excitation by pyrethroids, or whether they may contribute to development of an adverse health effect. Regardless, these data demonstrate alterations in gene transcription in cortex at low doses of pyrethroids that produce only mild effects observed in the whole animal.

Overall, increased expression of $c$-fos, Egr1 and Camk1g in the present study are most likely regulated by pyrethroidinduced changes in the neuronal firing patterns of cortical neurons. The increased expression of Gpd1 and Fkbp51 mRNA indicates an indirect effect on glia due to non-specific activation of the HPA-axis.

\section{Pyrethroid effects on branching morphogenesis}

The SAFE analyses yielded an enrichment of the category 'morphogenesis of a branching structure' for both pyrethroids. This was due to dose-dependent changes in expression at $6 \mathrm{~h}$ for several genes that control neurite branching and morphogenesis including Cxcl12, Notch1 and $\beta$-catenin [100-102]. A major function of this group of genes is thought to involve the regulation of neuronal morphogenesis during development. It is unknown whether the same gene categories would show enrichment at sampling times other than $6 \mathrm{~h}$ or whether these transient changes in gene expression leads to a significant change in neuronal morphology in the adult cortex. Herein, we also report that both pyrethroids increased neurite branch points in a developmental model of neurite growth [58], but did not alter total neurite length (Figure 6). The gene expression data from the present study are consistent with pyrethroid effects on neurite branching and not neurite length.

Overexpression of Notch1 in rat cortical neurons results in an increase in neuronal branching and an antagonism of neurite extension [100]. Likewise, overexpression of $\beta$-catenin and $\mathrm{Cxcl12}$ results in increased dendritic and axonal branch tip number, respectively, and has no or opposite effects on measures of length $[101,102]$. Transcripts for these genes are upregulated following pyrethroid exposure in the present microarray data (see Figure 5 heatmaps) and suggest that pyrethroids affect the developmental morphogenesis of neurons. However, these data are not consistent with the results of two previous studies of pyrethroid effects on developmental neuronal outgrowth. Treatment of developing X. laevis neurons with $10 \mathrm{nM}$ deltamethrin resulted in an increase in total neurite length in the presence of extracellular $\mathrm{Ca}^{+2}$ [103]. In contrast, exposure of N2A neuroblastoma or C6 glioma cells to the pyrethroid cypermethrin resulted in no effect on morphology [104]. The disparity between the results from these studies and the present study may be due to differences in the experimental conditions (cell types, media, exposure durations, etc.), all of which are known to impact neuronal outgrowth [105]. Preliminary experiments in PC-12 neuroblastoma cells (data not shown) did not demonstrate any effects on neurite branching or length. The present data is the first to demonstrate an effect of pyrethroids on the branching morphology of primary cultured neurons.

Disruption of neuronal morphogenesis in the developing nervous system by pyrethroids could result in detrimental effects on neurological function later in life. Intermittent exposure to stimulant drugs such as amphetamine can produce an increase in dendritic branching in vivo in both juvenile and adult rats [106-108]. These morphological changes are hypothesized to underlie some of the adverse neurological effects associated with abuse of stimulant drugs (e.g., learning deficits) $[106,109]$. In addition, lead exposure during development results in neurological deficits that have been associated with changes in neuronal morphology [110-112]. Both lead and stimulant drugs facilitate neurite outgrowth in in vitro cell culture models that is similar, but not identical, to the increased branching observed with pyrethroids in the present study [113117]. Several questions remain to be addressed before definitive conclusions regarding pyrethroid effects on neuronal morphogenesis can be made, including: 1) whether or not pyrethroid-induced changes in morphology occur in vivo, 2) are effects on morphogenesis specific to cortical neurons, and 3) do all compounds in the pyrethroid class produce the same types of effects on neuronal branching morphogenesis?

\section{Conclusion}

The present study has identified a group of genes whose transcription is altered in a dose-dependent manner in the rat cortex following in vivo pyrethroid exposure. A majority of the gene expression changes observed in this study are consistent with the induction of neuronal hyperexcitability by pyrethroids. The gene expression changes observed are transient, comparable between the two pyrethroids tested and provide insight into the cellular response of the neurons downstream of the pharmacological effects of these compounds at the neuronal membrane. Most importantly, this study provides evidence that branching of cortical neurons is increased by pyrethroids, suggesting the neurotoxic action of these compounds may include effects on neuronal morphology.

\section{Abbreviations}

B3galt3: UDP-Gal:betaGlcNAc beta 1,3-galactosyltransferase, polypeptide 3; Bcat: branched chain aminotransferase 1, cytosolic; Bdnf: brain derived neurotrophic 
factor; Bves: blood vessel epicardial substance; $c$-fos: FBJ murine osteosarcoma viral oncogene homolog; Camk1g: calcium/calmodulin-dependent protein kinase I gamma; Crh: corticotropin releasing hormone; Cryab: crystallin, alpha B; Cxcl12: chemokine (C-X-C motif) ligand 12; Ddc: dopa decarboxylase; Dusp6: dual specificity phosphatase 6; Dync1i1: dynein cytoplasmic 1 intermediate chain 1; $E D L$ : equipotent dose level; Egr1: early growth response 1; Ets2: v-ets erythroblastosis virus E26 oncogene homolog 2; Fbxo22: F-box only protein 22; Finb: ras responsive element binding protein 1 (predicted); Fkbp51: FK506 binding protein 5; GCOS: GeneChip ${ }^{\varpi}$ Operating Software; Gna14: guanine nucleotide binding protein, alpha 14; Gpd1: glycerol-3-phosphate dehydrogenase 1; Heatr1: HEAT repeat containing 1 (predicted); HPA - hypothalamic-pituitary-adrenal axis; Hsp27: heat shock $27 \mathrm{kDa}$ protein 1; Hyou1: hypoxia up-regulated 1; Igfpb3: insulinlike growth factor binding protein 3; Klf4: Kruppel-like factor 4; Klf10: Kruppel-like factor 10; Lrg1: leucine-rich alpha-2-glycoprotein 1; Lpen2: lipin 2 (predicted); Max: Max protein; Medl19: mediator of RNA polymerase II transcription, subunit 19 homolog; mRNA: messenger ribonucleic acid; Nedd4l: neural precursor cell expressed, developmentally down-regulated 4-like; Nr4a3: nuclear receptor subfamily 4, group A, member 3; Pde10a: phosphodiesterase 10A; Pdlm7: PDZ and LIM domain protein 7; PIR: penalized isotonic regression; Pld1 - phospholipase D1; Polr2c: polymerase (RNA) II (DNA directed) polypeptide C, $33 \mathrm{kDa}$; Prim2: DNA primase, p58 subunit; qRT-PCR: quantitative real-time polymerase chain reaction; Rassf5: ras association (RalGDS/AF-6) domain family 5; Ret: ret proto-oncogene; Rimbp2: RIMS binding protein 2; Rkhd3: ring finger and $\mathrm{KH}$ domain containing 3 (predicted); RMA: Robust Multi-array Average; SAFE: Significant Analysis of Function and Expression; SAM: Significant Analysis of Microarrays; Siat7E: sialyltransferase 7E; Slc39a8: solute carrier family 39 (zinc transporter), member 8; Slc40a1: solute carrier family 40 (iron-regulated transporter), member 1; Slit2: slit homolog 2; Sta2: stefin A2 (predicted); Tcfcp2l1: transcription factor CP2-like 1; Timp3: tissue inhibitor of metalloproteinase 3; Tmem10: transmembrane protein 10; Usp54: ubiquitin specific peptidase 54; Vdac1: voltage-dependent anion channel 1; Wrnip1: Werner helicase interacting protein $1 ; X d h$ : xanthine dehydrogenase; Zcch8: zinc finger, CCHC domain containing 8 (predicted)

\section{Authors' contributions}

JAH guided the study designs, carried out all RNA extractions, qRT-PCR experiements and data analyses, performed microarray data analyses and drafted the manuscript. FAW and ZL performed the penalized isotonic regression and SAFE analyses and provided valuable input on microarray analysis methods. NMR and WRM performed neuronal morphogenesis assays. RTV provided pharmacokinetic predictions of target tissue doses. KMC participated in study design, manuscript preparation and interpretation of this work.

\section{Additional material}

\begin{abstract}
Additional file 1
Comparison of mean coefficients of variation (CV) between GCOSv1.2 and RMA microarray expression summaries. For each expression summary calculation method, all 31,042 probe sets present on the Affymetrix Rat 2302.0 GeneChip array were sorted based on the mean expression summary within the control group and divided into equally sized percentile ranges in ascending order. CV's were calculated for each individual probe set within each dose group. The mean CV for each percentile range was then calculated across probe sets for each dose group. Expression summaries calculated using RMA consistently reduces the variability of the expression summaries across the entire data set when compared to GCOSv1.2. A dramatic decrease in variability is observed in the lower $50 \%$ of the data set.

Click here for file

[http://www.biomedcentral.com/content/supplementary/1471-

2164-9-546-S1.doc]
\end{abstract}

\section{Additional file 2}

Taqman $^{\varpi}$ qRT-PCR assay information.

Click here for file

[http://www.biomedcentral.com/content/supplementary/1471-

2164-9-546-S2.doc]

\section{Additional file 3}

List of probe sets with dose-dependent changes in expression for deltamethrin. Affymetrix probe set IDs without a gene symbol are expressed sequence tags (ESTs). Probe sets with arrows correspond to genes examined by qRT-PCR. Positive SAM $\mathrm{d}_{\mathrm{i}}$ or PIR $\mathrm{M}_{\mathrm{i}}$ scores denote upregulated probe sets. Negative SAM $\mathrm{d}_{\mathrm{i}}$ or PIR $\mathrm{M}_{\mathrm{i}}$ scores denote downregulated probe sets.

Click here for file

[http://www.biomedcentral.com/content/supplementary/14712164-9-546-S3.doc]

\section{Additional file 4}

List of probe sets with dose-dependent changes in expression for permethrin. Affymetrix probe set IDs without a gene symbol are expressed sequence tags (ESTs). Probe sets with arrows correspond to genes examined by qRT-PCR. Positive $S A M \mathrm{~d}_{\mathrm{i}}$ or PIR $\mathrm{M}_{\mathrm{i}}$ scores denote upregulated probe sets. Negative SAM $\mathrm{d}_{\mathrm{i}}$ or PIR $\mathrm{M}_{\mathrm{i}}$ scores denote downregulated probe sets.

Click here for file

[http://www.biomedcentral.com/content/supplementary/14712164-9-546-S4.doc] 


\author{
Additional file 5 \\ Two-way analysis of variance (ANOVA) for qRT-PCR time course \\ data. \\ Click here for file \\ [http://www.biomedcentral.com/content/supplementary/1471- \\ 2164-9-546-S5.doc]
}

\section{Acknowledgements}

JA Harrill was funded through the EPA/UNC Toxicology Research Program, Training Agreement (CR833237) during this work and previously funded through National Institute of Environmental Health Science Training Grant (T32-ES07/26). This document has been reviewed by the National Health and Environmental Effects Research Laboratory and approved for publication. Approval does not signify that the contents reflect the views of the agency, nor does mention of trade names or commercial products constitute endorsement or recommendation for use. The authors would like to thank Drs. Susan Hester and Ram Ramabhadran for comments on a previous version of this manuscript and Brian Robinette for work in preparing neuronal cell cultures.

\section{References}

I. Amweg EL, Weston DP, Ureda NM: Use and toxicity of pyrethroid pesticides in the Central Valley, California, USA. Environ Toxicol Chem 2005, 24(4):966-972.

2. Qin S, Budd R, Bondarenko S, Liu W, Gan J: Enantioselective degradation and chiral stability of pyrethroids in soil and sediment. J Agric Food Chem 2006, 54(I 4):5040-5045.

3. Colt JS, Lubin J, Camann D, Davis S, Cerhan J, Severson RK, Cozen W, Hartge P: Comparison of pesticide levels in carpet dust and self-reported pest treatment practices in four US sites. J Expo Anal Environ Epidemiol 2004, I 4(I):74-83.

4. Tulve NS, Jones PA, Nishioka MG, Fortmann RC, Croghan CW, Zhou JY, Fraser A, Cavel C, Friedman W: Pesticide measurements from the first national environmental health survey of child care centers using a multi-residue GC/MS analysis method. Environ Sci Technol 2006, 40(20):6269-6274.

5. Leng $\mathrm{G}$, Kuhn $\mathrm{KH}$, Idel $\mathrm{H}$ : Biological monitoring of pyrethroids in blood and pyrethroid metabolites in urine: applications and limitations. Sci Total Environ 1997, 199(I-2): 173-181.

6. Soderlund DM, Clark JM, Sheets LP, Mullin LS, Piccirillo VJ, Sargent D, Stevens JT, Weiner ML: Mechanisms of pyrethroid neurotoxicity: implications for cumulative risk assessment. Toxicology 2002, I II(I):3-59.

7. Narahashi T: Neuronal ion channels as the target sites of insecticides. Pharmacol Toxicol 1996, 79(I): I-I4.

8. Ginsburg KS, Narahashi T: Differential sensitivity of tetrodotoxin-sensitive and tetrodotoxin-resistant sodium channels to the insecticide allethrin in rat dorsal root ganglion neurons. Brain Res 1993, 627(2):239-248.

9. Motomura H, Narahashi T: Interaction of tetramethrin and deltamethrin at the single sodium channel in rat hippocampal neurons. Neurotoxicology 200I, 22(3):329-339.

10. Song JH, Narahashi T: Modulation of sodium channels of rat cerebellar Purkinje neurons by the pyrethroid tetramethrin. J Pharmacol Exp Ther 1996, 277(I):445-453.

II. Smith TJ, Soderlund DM: Action of the pyrethroid insecticide cypermethrin on rat brain Ila sodium channels expressed in xenopus oocytes. Neurotoxicology 1998, 19(6):823-832.

12. Choi JS, Soderlund DM: Structure-activity relationships for the action of I I pyrethroid insecticides on rat $\mathrm{Na} v$ I.8 sodium channels expressed in Xenopus oocytes. Toxicol Appl Pharmacol 2006, 2 II (3):233-244.

13. Shafer TJ, Meyer DA, Crofton KM: Developmental neurotoxicity of pyrethroid insecticides: critical review and future research needs. Environ Health Perspect 2005, I I 3(2): 1 23-136.

14. Shafer T], Meyer DA: Effects of pyrethroids on voltage-sensitive calcium channels: a critical evaluation of strengths, weak- nesses, data needs, and relationship to assessment of cumulative neurotoxicity. Toxicol Appl Pharmacol 2004, 196(2):303-318.

15. Symington SB, Clark JM: Action of deltamethrin on N-Type (Cav2.2) voltage-sensitive calcium channels in rat brain. Pesticide Biochemistry and Physiology 2005, 82: I-I5.

16. Burr SA, Ray DE: Structure-activity and interaction effects of 14 different pyrethroids on voltage-gated chloride ion channels. Toxicol Sci 2004, 77(2):34I-346.

17. Ray DE, Fry JR: A reassessment of the neurotoxicity of pyrethroid insecticides. Pharmacol Ther 2006, I I I(I): I74-193.

18. Ray DE: An EEG investigation of decamethrin-induced choreoathetosis in the rat. Exp Brain Res 1980, 38(2):221-227.

19. Wright CDP, Forshaw PJ, Ray DE: Classification of the actions of ten pyrethroid insecticides in the rat, using the trigeminal reflex and skeletal muscle as test systems. Pesticide Biochemistry and Physiology 1988, 30(1):79-86.

20. Vijverberg HP, Bercken J van den: Neurotoxicological effects and the mode of action of pyrethroid insecticides. Crit Rev Toxicol 1990, 2 I(2): 105-126.

21. Ray DE: Pyrethroid Insecticides: Mechanisms of Toxicity, Systematic Poisoning Syndromes, Parethesia, and Therapy. In Handbook of Pesticide Toxicology Volume 2. 2nd edition. Edited by: Krieger RI. San Diego, CA: Academic Press; 200I:I289-1303.

22. Fields RD, Lee PR, Cohen JE: Temporal integration of intracellular $\mathrm{Ca2}+$ signaling networks in regulating gene expression by action potentials. Cell Calcium 2005, 37(5):433-442.

23. Bading $\mathrm{H}$ : Transcription-dependent neuronal plasticity the nuclear calcium hypothesis. Eur J Biochem 2000, 267(17):5280-5283.

24. McClung CA, Nestler EJ: Neuroplasticity mediated by altered gene expression. Neuropsychopharmacology 2008, 33(I):3-I7.

25. Bahi A, Dreyer JL: Cocaine-induced expression changes of axon guidance molecules in the adult rat brain. Mol Cell Neurosci 2005, 28(2):275-29I.

26. Cai NS, McCoy MT, Ladenheim B, Lyles J, Ali SF, Cadet JL: Serial analysis of gene expression in the rat striatum following methamphetamine administration. Ann N Y Acad Sci 2006, 1074: 13-30.

27. Xiang G, Pan L, Xing W, Zhang L, Huang L, Yu J, Zhang R, Wu J, Cheng J, Zhou $Y$ : Identification of activity-dependent gene expression profiles reveals specific subsets of genes induced by different routes of $\mathrm{Ca}(2+)$ entry in cultured rat cortical neurons. J Cell Physiol 2007, 21 2(I): I26-136.

28. Anadon A, Martinez-Larranaga MR, Diaz MJ, Bringas P: Toxicokinetics of permethrin in the rat. Toxicol Appl Pharmacol 199I, I IO(I): $1-8$

29. Hassouna I, Wickert H, el-Elaimy I, Zimmermann M, Herdegen T: Systemic application of pyrethroid insecticides evokes differential expression of c-Fos and c-Jun proteins in rat brain. Neurotoxicology 1996, 17(2):415-431.

30. Anadon A, Martinez-Larranaga MR, Fernandez-Cruz ML, Diaz MJ, Fernandez MC, Martinez MA: Toxicokinetics of deltamethrin and its 4'-HO-metabolite in the rat. Toxicol Appl Pharmacol 1996, I4I(I):8-16.

31. Condes-Lara M, Graff-Guerrero A, Vega-Riveroll L: Effects of cypermethrin on the electroencephalographic activity of the rat: a model of chemically induced seizures. Neurotoxicol Teratol I 999, 2 I (3):293-298.

32. Meyer DA, Carter JM, Johnstone AF, Shafer TJ: Pyrethroid modulation of spontaneous neuronal excitability and neurotransmission in hippocampal neurons in culture. Neurotoxicology 2008, 29(2):213-225.

33. Wolansky MJ, Gennings C, Crofton KM: Relative potencies for acute effects of pyrethroids on motor function in rats. Toxicol Sci 2006, 89(I):27I-277

34. Tusher VG, Tibshirani R, Chu G: Significance analysis of microarrays applied to the ionizing radiation response. Proc Natl Acad Sci U S A 200I, 98(9):5II6-5I2I.

35. Hu J, Kapoor M, Zhang W, Hamilton SR, Coombes KR: Analysis of dose-response effects on gene expression data with comparison of two microarray platforms. Bioinformatics 2005, 2I( I 7):3524-3529.

36. Barry WT, Nobel AB, Wright FA: Significance analysis of functional categories in gene expression studies: a structured permutation approach. Bioinformatics 2005, 2 I(9): 1943-1949. 
37. Tully DB, Bao W, Goetz AK, Blystone CR, Ren H, Schmid JE, Strader LF, Wood CR, Best DS, Narotsky MG, et al.: Gene expression profiling in liver and testis of rats to characterize the toxicity of triazole fungicides. Toxicol Appl Pharmacol 2006, 2 I 5(3):260-273.

38. Irizarry RA, Hobbs B, Collin F, Beazer-Barclay YD, Antonellis KJ, Scherf U, Speed TP: Exploration, normalization, and summaries of high density oligonucleotide array probe level data. Biostatistics 2003, 4(2):249-264.

39. Affymetrix Inc: GeneChip Expression Analysis: Data Analysis Fundamentals (Part No. 70I 190). Santa Clara, CA: Affymetrix Inc; 2002.

40. Chu G, Balasubramanian N, Tibshirani R, Tusher VG: SAM "Significance Analysis of Microarrays" Users guide and technical document. Palo Alto, CA: Stanford University; 2005.

4I. Dunnett CW: A multiple comparison procedure for comparing several treatments with a control. Journal of the American Statistical Association 1950, 50:1096- II21.

42. Applied Biosystems Inc: The Design Process for a New Generation of Quantitative Gene Expression Analysis Tools (Publication I27WP02-02). Foster City, CA: Applied Biosystems Inc; 2006.

43. Applied Biosystems Inc: Amplification Efficiency of Taqman Assays-on-Demand Gene Expression Products (Publication I 27AP05-0I). Foster City, CA: Applied Biosystems Inc; 2004.

44. Livak KJ, Schmittgen TD: Analysis of relative gene expression data using real-time quantitative PCR and the 2(-Delta Delta C(T)) Method. Methods 200I, 25(4):402-408.

45. Dennis G Jr, Sherman BT, Hosack DA, Yang J, Gao W, Lane HC, Lempicki RA: DAVID: Database for Annotation, Visualization, and Integrated Discovery. Genome Biol 2003, 4(5):P3.

46. Gentleman RC, Carey V], Bates DM, Bolstad B, Dettling M, Dudoit S, Ellis B, Gautier L, Ge Y, Gentry J, et al:: Bioconductor: open software development for computational biology and bioinformatics. Genome Biol 2004, 5( I 0):R80.

47. Signifcance Analysis of Function and Expression, User's Guide [http://bioconductor.org/packages//.8/bioc/vignettes/safe/ inst/doc/SAFEmanual.pdf]

48. Pearson K: On the probability that two independent distributions of frequency are really samples from the same population. Biometrika |9|I, 8:250-254.

49. Mootha VK, Lindgren CM, Eriksson KF, Subramanian A, Sihag S, Lehar J, Puigserver P, Carlsson E, Ridderstrale M, Laurila E, et al.: PGC I alpha-responsive genes involved in oxidative phosphorylation are coordinately downregulated in human diabetes. Nat Genet 2003, 34(3):267-273.

50. Barry WT, Nobel AB, Wright FA: A statistical framework for testing functional categories in microarray data. Annals of Applied Statistics 2008 in press.

51. Yekutieli D, Benjamini Y: Resampling-based false discovery rate controlling multiple test procedures for correlated test statistics. J Statist Plann Inference 1999, 82:17|-196.

52. Fisher RA: Statistical Methods for Research Workers. Third edition. Oliver and Boyd, London; 1999:283.

53. Littell RC, Folks JL: Asymptotic optimality of Fisher's method of combining tests II. Journal of the American Statistical Association 1973, 68:193-194.

54. Benjamini $\mathrm{Y}$, Hochberg $\mathrm{Y}$ : Controlling the false discovery rate: a practical and powerful approach to multiple testing. J Roy Statist Soc Ser B 1995, 232:437-443.

55. Chandler LJ, Newsom H, Sumners C, Crews F: Chronic ethanol exposure potentiates NMDA excitotoxicity in cerebral cortical neurons. I Neurochem 1993, 60(4):|578-I58I.

56. Tornero-Velez R, Scollon EJ, Starr J, Hughes MF, DeVito MJ, Dary CC: Pharmacokinetic/Pharmacodynamic Modeling of Permethrin in the Rat. The Toxicologist 2007, 96:81.

57. Mirfazaelian A, Kim KB, Anand SS, Kim HJ, Tornero-Velez R, Bruckner JV, Fisher JW: Development of a physiologically based pharmacokinetic model for deltamethrin in the adult male Sprague-Dawley rat. Toxicol Sci 2006, 93(2):432-442.

58. Radio NM, Breier JM, Shafer T], Mundy WR: Assessment of chemical effects on neurite outgrowth in PCI 2 cells using high content screening. Toxicol Sci 2008, I05(I): I06-II8.

59. De Kloet ER, Vreugdenhil E, Oitzl MS, Joels M: Brain corticoster oid receptor balance in health and disease. Endocr Rev 1998, | 9(3):269-301.
60. West AE, Griffith EC, Greenberg ME: Regulation of transcription factors by neuronal activity. Nat Rev Neurosci 2002, 3(12):921-93|

6I. Schulman H, Roberts JL: Intracellular Signaling. In Fundamental Neuroscience Second edition. Edited by: Squire LR, Bloom FE, McConnell SK, Roberts JL, Spitzer NC, Zigmond MJ. New York: Academic Press; 2003:259-297.

62. Schoneveld OJ, Gaemers IC, Lamers WH: Mechanisms of glucocorticoid signalling. Biochim Biophys Acta 2004, I 680(2): | | 4- | 28.

63. Cull-Candy S, Brickley S, Farrant M: NMDA receptor subunits: diversity, development and disease. Curr Opin Neurobiol 200I, I I(3):327-335

64. Ogata N, Ohishi Y: Molecular diversity of structure and function of the voltage-gated $\mathbf{N a}+$ channels. Jpn J Pharmacol 2002, 88(4):365-377.

65. Catterall WA, Striessnig J, Snutch TP, Perez-Reyes E: International Union of Pharmacology. XL. Compendium of voltage-gated ion channels: calcium channels. Pharmacol Rev 2003 55(4):579-58।

66. Farrant $M$, Kaila $K$ : The cellular, molecular and ionic basis of GABA(A) receptor signalling. Prog Brain Res 2007, 160:59-87.

67. Shafer TJ, Rijal SO, Gross GW: Complete inhibition of spontaneous activity in neuronal networks in vitro by deltamethrin and permethrin. Neurotoxicology 2008, 29(2):203-2I2.

68. Paillart C, Boudier JL, Boudier JA, Rochat H, Couraud F, Dargent B: Activity-induced internalization and rapid degradation of sodium channels in cultured fetal neurons. J Cell Biol 1996, I34(2):499-509.

69. Giraud P, Alcaraz G, Jullien F, Sampo B, Jover E, Couraud F, Dargent $B$ : Multiple pathways regulate the expression of genes encoding sodium channel subunits in developing neurons. Brain Res Mol Brain Res 1998, 56( I-2):238-255.

70. Shiraishi S, Yanagita T, Kobayashi H, Uezono Y, Yokoo H, Minami SI, Takasaki $M$, Wada $A$ : Up-regulation of cell surface sodium channels by cyclosporin A, FK506, and rapamycin in adrenal chromaffin cells. J Pharmacol Exp Ther 200I, 297(2):657-665.

7I. Kim J, Jung SC, Clemens AM, Petralia RS, Hoffman DA: Regulation of dendritic excitability by activity-dependent trafficking of the A-type K+ channel subunit Kv4.2 in hippocampal neurons. Neuron 2007, 54(6):933-947.

72. Wu A, Liu Y: Prolonged expression of c-Fos and c-Jun in the cerebral cortex of rats after deltamethrin treatment. Brain Res Mol Brain Res 2003, I I O(I): |47-I5I.

73. Zangenehpour $S$, Chaudhuri A: Differential induction and decay curves of c-fos and zif268 revealed through dual activity maps. Brain Res Mol Brain Res 2002, I 09(I-2):22I-225.

74. Patra RC, Blue ME, Johnston MV, Bressler J, Wilson MA: Activitydependent expression of Egr I mRNA in somatosensory cortex of developing rats. J Neurosci Res 2004, 78(2):235-244.

75. Steward O, Wallace CS, Lyford GL, Worley PF: Synaptic activation causes the mRNA for the IEG Arc to localize selectively near activated postsynaptic sites on dendrites. Neuron 1998 , 2 I (4):74 |-75|

76. Dassesse D, Vanderwinden JM, Goldberg I, Vanderhaeghen JJ, Schiffmann SN: Caffeine-mediated induction of c-fos, zif-268 and arc expression through $\mathrm{Al}$ receptors in the striatum: different interactions with the dopaminergic system. Eur J Neurosci |999, I I(9):3101-3 | |4.

77. Guzowski JF, McNaughton BL, Barnes CA, Worley PF: Environment-specific expression of the immediate-early gene Arc in hippocampal neuronal ensembles. Nat Neurosci 1999, 2(12): I| $20-|| \mid 24$.

78. Clayton DF: The genomic action potential. Neurobiol Learn Mem 2000, 74(3): $185-216$.

79. Crofton KM, Reiter LW: Effects of two pyrethroid insecticides on motor activity and the acoustic startle response in the rat. Toxicol Appl Pharmacol 1984, 75(2):3 18-328.

80. Wayman GA, Impey S, Marks D, Saneyoshi T, Grant WF, Derkach V, Soderling TR: Activity-dependent dendritic arborization mediated by CaM-kinase I activation and enhanced CREBdependent transcription of Wnt-2. Neuron 2006, 50(6):897-909.

81. Takemoto-Kimura S, Ageta-Ishihara N, Nonaka M, Adachi-Morishima A, Mano T, Okamura M, Fujii H, Fuse T, Hoshino M, Suzuki S, et al.: Regulation of dendritogenesis via a lipid-raft-associated 
Ca2+/calmodulin-dependent protein kinase CLICK-III/CaMKIgamma. Neuron 2007, 54(5):755-770.

82. Fatemi SH, Reutiman TJ, Folsom TD, Bell C, Nos L, Fried P, Pearce DA, Singh S, Siderovski DP, Willard FS, et al.: Chronic olanzapine treatment causes differential expression of genes in frontal cortex of rats as revealed by DNA microarray technique. Neuropsychopharmacology 2006, 3 I (9): |888-|899.

83. Korostynski M, Piechota M, Kaminska D, Solecki W, Przewlocki R: Morphine effects on striatal transcriptome in mice. Genome Biol 2007, 8(6):RI 28.

84. Stanzione P, Stefani A, Bernardi G: Morphine induces a spontaneous and evoked bursting activity in rat cortical neurons by adding a postsynaptic active mechanism to the synaptic input: an intracellular study in vivo. Neuroscience 1988, 26(I):45-53.

85. Gronier BS, Rasmussen K: Electrophysiological effects of acute and chronic olanzapine and fluoxetine in the rat prefrontal cortex. Neurosci Lett 2003, 349(3):196-200.

86. Leveille PJ, McGinnis JF, Maxwell DS, de Vellis J: Immunocytochemical localization of glycerol-3-phosphate dehydrogenase in rat oligodendrocytes. Brain Res 1980, 196(2):287-305

87. Baughman G, Wiederrecht GJ, Campbell NF, Martin MM, Bourgeois S: FKBP5I, a novel T-cell-specific immunophilin capable of calcineurin inhibition. Mol Cell Biol 1995, I5(8):4395-4402.

88. Cheng JD, de Vellis J: Oligodendrocytes as glucocorticoids target cells: functional analysis of the glycerol phosphate dehydrogenase gene. J Neurosci Res 2000, 59(3):436-445.

89. Hubler TR, Scammell JG: Intronic hormone response elements mediate regulation of FKBP5 by progestins and glucocorticoids. Cell Stress Chaperones 2004, 9(3):243-252.

90. Nicols NR, Dokas L, Ting SM, Kumar S, de Vellis J, Shors TJ, Uenishi $\mathrm{N}$, Thompson RF, Finch CE: Hippocampal responses to corticosterone and stress, one of which is the $35,000 \mathrm{M}(\mathrm{r})$ protein, glycerol phosphate dehydrogenase. I Neuroendocrinol 1996 , 8(I I):867-876.

91. Baughman G, Wiederrecht GJ, Chang F, Martin MM, Bourgeois S: Tissue distribution and abundance of human FKBP5I, and FK506-binding protein that can mediate calcineurin inhibition. Biochem Biophys Res Commun 1997, 232(2):437-443.

92. de Boer SF, Gugten J van der, Slangen JL, Hijzen TH: Changes in plasma corticosterone and catecholamine contents induced by low doses of deltamethrin in rats. Toxicology 1988, 49(23):263-270.

93. Deutch AY, Roth RH: Neurotransmitters. In Fundamental Neuroscience Second edition. Edited by: Squire LR, Bloom FE, McConnell SK, Roberts JL, Spitzer NC, Zigmond MJ. New York: Academic Press; 2003:163-196.

94. Martinez-Larranaga MR, Anadon A, Martinez MA, Martinez M, Castellano VJ, Diaz MJ: 5-HT loss in rat brain by type II pyrethroid insecticides. Toxicol Ind Health 2003, 19(7-10): 147-155.

95. Liu GP, Ma Q, Shi N: Tyrosine hydroxylase as a target for deltamethrin in the nigrostriatal dopaminergic pathway. Biomed Environ Sci 2006, I9(I):27-34.

96. Liu GP, Shi N: The inhibitory effects of deltamethrin on dopamine biosynthesis in rat PCI 2 cells. Toxicol Lett 2006 161(3):195-199.

97. Crofton KM, Kehn LS, Gilbert ME: Vehicle and route dependent effects of a pyrethroid insecticide, deltamethrin, on motor function in the rat. Neurotoxicol Teratol 1995, I 7(4):489-495.

98. Peele DB, Crofton KM: Pyrethroid effects on schedule-controlled behavior: time and dosage relationships. Neurotoxicol Teratol 1987, 9(5):387-394.

99. McDaniel KL, Moser VC: Utility of a neurobehavioral screening battery for differentiating the effects of two pyrethroids, permethrin and cypermethrin. Neurotoxicol Teratol 1993, I5(2):7|-83.

100. Redmond L, Oh SR, Hicks C, Weinmaster G, Ghosh A: Nuclear Notch I signaling and the regulation of dendritic development. Nat Neurosci 2000, 3(1):30-40.

10I. Yu X, Malenka RC: Beta-catenin is critical for dendritic morphogenesis. Nat Neurosci 2003, 6(I I): I I69-II77.

102. Pujol F, Kitabgi P, Boudin H: The chemokine SDF-I differentially regulates axonal elongation and branching in hippocampal neurons. J Cell Sci 2005, I I 8(Pt 5): I07|-1080.
103. Lautermilch NJ, Spitzer NC: Regulation of calcineurin by growth cone calcium waves controls neurite extension. I Neurosci 2000, 20(I):3I5-325.

104. Flaskos J, Harris W, Sachana M, Munoz D, Tack J, Hargreaves Al: The effects of diazinon and cypermethrin on the differentiation of neuronal and glial cell lines. Toxicol Appl Pharmacol 2007, 219(2-3): $172-180$

105. Radio NM, Mundy WR: Developmental neurotoxicity testing in vitro: models for assessing chemical effects on neurite outgrowth. Neurotoxicology 2008, 29(3):36I-376.

106. Robinson TE, Kolb B: Structural plasticity associated with exposure to drugs of abuse. Neuropharmacology 2004, 47(Suppl I):33-46.

107. Diaz Heijtz R, Kolb B, Forssberg H: Can a therapeutic dose of amphetamine during pre-adolescence modify the pattern of synaptic organization in the brain? Eur J Neurosci 2003, I 8(I 2):3394-3399.

108. Robinson TE, Kolb B: Alterations in the morphology of dendrites and dendritic spines in the nucleus accumbens and prefrontal cortex following repeated treatment with amphetamine or cocaine. Eur J Neurosci 1999, I I(5): I598-I604.

109. Gonzalez CL, Gharbawie OA, Whishaw IQ, Kolb B: Nicotine stimulates dendritic arborization in motor cortex and improves concurrent motor skill but impairs subsequent motor learning. Synapse 2005, 55(3): $183-191$.

I 10. Petit TL, LeBoutillier JC: Effects of lead exposure during development on neocortical dendritic and synaptic structure. Exp Neurol 1979, 64(3):482-492.

III. McConnell P, Berry M: The effects of postnatal lead exposure on Purkinje cell dendritic development in the rat. Neuropathol Appl Neurobiol 1979, 5(2): I I5-132.

112. Costa LG, Aschner M, Vitalone A, Syversen T, Soldin OP: Developmental neuropathology of environmental agents. Annu Rev Pharmacol Toxicol 2004, 44:87-I 10.

1 13. Kern M, Audesirk T, Audesirk G: Effects of inorganic lead on the differentiation and growth of cortical neurons in culture. Neurotoxicology 1993, I4(2-3):319-327.

114. Audesirk T, Cabell L: Nanomolar concentrations of nicotine and cotinine alter the development of cultured hippocampal neurons via non-acetylcholine receptor-mediated mechanisms. Neurotoxicology 1999, 20(4):639-646.

I I5. Crumpton T, Atkins DS, Zawia NH, Barone S Jr: Lead exposure in pheochromocytoma (PCI2) cells alters neural differentiation and SpI DNA-binding. Neurotoxicology 200I, 22(I):49-62.

116. Park YH, Kantor L, Guptaroy B, Zhang M, Wang KK, Gnegy ME: Repeated amphetamine treatment induces neurite outgrowth and enhanced amphetamine-stimulated dopamine release in rat pheochromocytoma cells ( $\mathrm{PCI} 2$ cells) via a protein kinase $\mathrm{C}$ - and mitogen activated protein kinasedependent mechanism. J Neurochem 2003, 87(6): I546-I557.

I I7. Park YH, Kantor L, Wang KK, Gnegy ME: Repeated, intermittent treatment with amphetamine induces neurite outgrowth in rat pheochromocytoma cells (PCI2 cells). Brain Res 2002, 95 I (I):43-52.

Publish with Bio Med Central and every scientist can read your work free of charge

"BioMed Central will be the most significant development for disseminating the results of biomedical research in our lifetime. "

Sir Paul Nurse, Cancer Research UK

Your research papers will be:

- available free of charge to the entire biomedical community

- peer reviewed and published immediately upon acceptance

- cited in PubMed and archived on PubMed Central

- yours - you keep the copyright 